\title{
Arsenic Removal from Aqueous Solution Using Pure and Metal-Doped Titania Nanoparticles Coated on Glass Beads: Adsorption and Column Studies
}

\author{
M. Ihsan Danish, ${ }^{1}$ Ishtiaq A. Qazi, ${ }^{1}$ Akif Zeb, ${ }^{1}$ Amir Habib, ${ }^{2}$ \\ M. Ali Awan, ${ }^{1}$ and Zahiruddin Khan' \\ ${ }^{1}$ Institute of Environmental Science and Engineering (IESE), National University of Sciences and Technology (NUST), \\ H-12, Islamabad 44000, Pakistan \\ ${ }^{2}$ School of Chemical and Materials Engineering (SCME), National University of Sciences and Technology (NUST), \\ H-12, Islamabad 44000, Pakistan
}

Correspondence should be addressed to M. Ihsan Danish; midchemist@yahoo.com

Received 10 January 2013; Accepted 20 May 2013

Academic Editor: Takuya Tsuzuki

Copyright (C) 2013 M. Ihsan Danish et al. This is an open access article distributed under the Creative Commons Attribution License, which permits unrestricted use, distribution, and reproduction in any medium, provided the original work is properly cited.

Nanosized metal oxide, Titania, provides high surface area and specific affinity for the adsorption of heavy metals, including arsenic (As), which is posing a great threat to the world population due to its carcinogenic nature. In this study, As(III) adsorption was studied on pure and metal- (Ag- and Fe-) doped Titania nanoparticles. The nanoparticles were synthesized by liquid impregnation method with some modifications, with crystallite size in the range of 30 to $40 \mathrm{~nm}$. Band gap analysis, using Kubelka-Munk function showed a shift of absorption band from UV to visible region for the metal-doped Titania. Effect of operational parameters like dose of nanoparticles, initial As(III) concentration, and $\mathrm{pH}$ was evaluated at $25^{\circ} \mathrm{C}$. The data obtained gave a good fit with Langmuir and Freundlich isotherms and the adsorption was found to conform to pseudo-second-order kinetics. In batch studies, over $90 \%$ of arsenic removal was observed for both types of metal-doped Titania nanoparticles from a solution containing up to $2 \mathrm{ppm}$ of the heavy metal. Fixed bed columns of nanoparticles, coated on glass beads, were used for As(III) removal under different operating conditions. Thomas and Yoon-Nelson models were applied to predict the breakthrough curves and to find the characteristic column parameters useful for process design. The columns were regenerated using $10 \% \mathrm{NaOH}$ solution.

\section{Introduction}

Naturally occurring elemental arsenic is ubiquitous and is present in both organic and inorganic forms. It is the 20th most abundant in earth's crust, 14th in seawater, and 12th in the human body [1-3]. Natural water is mostly contaminated with the more toxic inorganic form rather than organic one. Over 200 different mineral forms of arsenic occur, of which Arsenates are about $60 \%$, sulfides and sulfosalts make $20 \%$, and arsenides, arsenites, oxides, silicates, and elemental arsenic make the remaining 20\% [3,4]. Anthropogenic sources exceed the natural sources of arsenic by $3: 1$ [3]. The major man-made sources of arsenic contamination are arsenial pesticides, fertilizers, dust of burning fossil fuel, animal, and industrial waste disposal [3].
In natural water, arsenic exists as inorganic arsenate $(\mathrm{As}(\mathrm{V}))$ and arsenite (As(III)). As(III) is mainly found as arsenious acid $\left(\mathrm{H}_{3} \mathrm{AsO}_{3}\right)$ and $\mathrm{As}(\mathrm{V})$, occurs as anionic species ( $\mathrm{HAsO}_{4}{ }^{2-}$ and $\mathrm{H}_{2} \mathrm{AsO}_{4}{ }^{-}$) [5]. Ground water mainly contains As(III) due to the prevailing reducing conditions, while $\mathrm{As}(\mathrm{V})$ is mainly found in the more oxidized surface waters. Inorganic arsenic has been made the top priority pollutant by USEPA [6], among which trivalent arsenic is about 60 times more toxic than oxidized pentavalent state [7]. Inorganic arsenic compounds are about 100 times more toxic than organic arsenic compounds.

Humans are exposed to arsenic contamination mainly through ingestion, inhalation, or skin adsorption; however, among these ingestion is the most predominant form of arsenic intake. Large doses of arsenic can result in acute 
toxic effects like gastrointestinal symptoms like vomiting, diarrhea, poor appetite, disturbance of cardiovascular and nervous systems functions, or even death in severe cases [810]. Continuous exposure to arsenic contaminated water, or food for several years can result in skin, kidney, bladder, and lung cancers [11]. Although it is present in air, water, and soil, the most direct source to which human population is exposed is drinking water contaminated with arsenic.

High concentration of arsenic in drinking water has been reported in many parts of the world, including Argentina, Bangladesh, China, Chile, Canada, Hungary, India, Japan, Mexico, Poland, Taiwan, and USA [12]. In Pakistan, 20\% of Punjab and $36 \%$ of Sindh population is exposed to Arsenic contamination over $10 \mu \mathrm{g} / \mathrm{L}$ in drinking water; similarly, $3 \%$ of Punjab and $16 \%$ of Sindh population is exposed to over $50 \mu \mathrm{g} / \mathrm{L}$ of arsenic in drinking water [13]. The most alarming situation exists in Kalalanwala village (East Punjab) where the arsenic concentration in groundwater is as high as $1900 \mu \mathrm{g} / \mathrm{L}$ [14]. Due to the widespread negative health effects of arsenic on humans, in $1993 \mathrm{WHO}$ lowered the permissible limit of arsenic in drinking water from $50 \mu \mathrm{g} / \mathrm{L}(0.05 \mathrm{mg} / \mathrm{L})$ to $10 \mu \mathrm{g} / \mathrm{L}$ $(0.01 \mathrm{mg} / \mathrm{L})$, and this provisional guideline level is retained by WHO in the latest edition of its standards $[15,16]$.

Many technologies are available for the removal of arsenic from water. Among these, adsorption has been widely used because of its simplicity in operation, greater removal efficiency, cost-effectiveness, and adsorbent disposal qualities [17]. Various natural and synthetic materials have been used for the removal of arsenic from drinking water. Some of the most widely used adsorbents include manganese and activated alumina [18, 19], iron oxide [20], Fe-Ce bimetallic oxide [21], zero-valent iron [22], red mud [23], and some other materials like activated carbon, fly ash, crab shells, coconut shells, and rice husks. There are, however, many problems associated with these adsorbents like low removal efficiency, no regeneration, their impurities, and slow kinetics [17]. For effective adsorption, the adsorbent must be efficient in removal, highly selective in adsorption, high adsorption capacity, cost-effective, safe in disposal, and have large surface area.

It has been reported that $\mathrm{As}(\mathrm{V})$ compared to $\mathrm{As}(\mathrm{III})$ is more readily adsorbed by various adsorbents, because As(III) is mainly present as nonionic $\mathrm{H}_{3} \mathrm{AsO}_{3}$ in natural water at near neutral $\mathrm{pH}$ [24-26]. Therefore, effective removal of arsenic from water needs preoxidation of As(III) to As(V) before adsorption [27]. Many oxidants, including chlorine [28], $\mathrm{Fe}(\mathrm{II}) / \mathrm{H}_{2} \mathrm{O}_{2}$ [29], hydrogen peroxide [30], $\mathrm{KMnO}_{4}$ [24], manganese dioxide [31, 32], oxygen and/or ozone [33], potassium ferrate [34], $\mathrm{UV} / \mathrm{H}_{2} \mathrm{O}_{2}$ [35], $\mathrm{UV} / \mathrm{Fe}(\mathrm{III})$ complexes $[36,37]$, and $\mathrm{UV} / \mathrm{TiO}_{2}[25,35,38-43]$ have been tested for oxidation of As(III) to As(V).

$\mathrm{TiO}_{2}$ due to its chemical stability, nontoxicity, low cost, and resistance to corrosion [44] possesses a high potential for arsenic removal. Being nanosized, titania has a large surface area for adsorption. It can not only oxidize As(III) to As(V) $[45,46]$ but also adsorb both these species from water [47-49].

In this study we have used pure and metal-doped titania nanoparticles, coated on glass beads for arsenic removal in a continuous flow system. The performance of titania coated glass beads evaluated through breakthrough studies by varying the column operation conditions, such as type of titania nanoparticles, bed depth, influent flow rate, and influent As(III) concentration. Thomas and Yoon-Nelson models were applied to column study. Column capacities were calculated.

\section{Material and Methods}

2.1. Material and Chemicals. All the solutions were prepared in deionized water $(\mathrm{EC}<0.7 \mu \mathrm{S} / \mathrm{cm}$, Labconco WaterPro PS). General purpose reagent titanium (IV) oxide (RiedelDeHaen) was used as a source of titania nanoparticles, nitrate salts of Fe (Merck, Germany) and Ag (Merck, Germany) were used as precursors for metals. Sodium arsenate, $\mathrm{Na}_{2} \mathrm{HAsO}_{4} \cdot 7 \mathrm{H}_{2} \mathrm{O}(\mathrm{BDH})$, was used as a source of arsenite (As(III)).

2.2. Arsenic Stock Solution. Arsenic (III) stock solution (100 ppm) was prepared by dissolving $420 \mathrm{mg}$ of sodium arsenate in $1 \mathrm{~L}$ of deionized water. The $\mathrm{pH}$ of the solution was adjusted to $7.0( \pm 0.1)$, using $0.1 \mathrm{M}$ nitric acid and $0.1 \mathrm{M} \mathrm{NaOH}$. The solution was shaken well and then stored in dark. Further dilutions were made using this solution.

2.3. Instrumentation. The quantitative determination of arsenic was done by atomic absorption spectrophotometer (AAS vario 6, analytic jena (Germany)) in hydride generation mode. A pH meter (CyberScan 500) was used to adjust the $\mathrm{pH}$ of the arsenic stock solution, with $0.1 \mathrm{M} \mathrm{HNO}_{3}$ and $0.1 \mathrm{M}$ $\mathrm{NaOH}$.

\section{Experimental}

3.1. Synthesis of Nanoparticles. Pure and metal-doped titania nanoparticles were prepared using liquid impregnation method $[50,51]$ as described below.

In $300 \mathrm{~mL}$ water in a beaker placed on a magnetic stirrer, 50 grams of GPR titania was added slowly and stirred for 24 hours. The titania suspension was then removed from the stirrer and allowed to stand for 24 hours, dried at $105^{\circ} \mathrm{C}$, ground using mortar and pestle, calcinated at $400^{\circ} \mathrm{C}$ in furnace for 6 hours, and then allowed to cool down at $10^{\circ} \mathrm{C}$ per minute. The nanoparticles were then transferred to a plastic bottle and placed in dark.

The metal doped nanoparticles were prepared using the same procedure, with $1 \%$ molar ratio of the metal salt being added to the solution before adding titania.

\subsection{Characterization of Nanoparticles}

3.2.1. S.E.M. Study. S.E.M. analysis of pure and metal-doped titania nanoparticles was carried out with JEOL JSM 6460 scanning electron microscope to observe the metal distribution on the surface of $\mathrm{TiO}_{2}$ in doped species. 
3.2.2. X-Ray Diffraction Analysis. The crystal phase and crystalline size of the prepared titania nanoparticles were determined by powder X-ray diffraction analysis. XRD studies of pure and doped $\mathrm{TiO}_{2}$ were carried out using 3040/60 XPert Pro PANalytical X-ray diffractometer using $\mathrm{CuK} \alpha$ radiation. The applied voltage and current were $40 \mathrm{kV}$ and $30 \mathrm{~mA}$, respectively. Scanning was done from $10^{\circ}$ to $80^{\circ}$ at a scan rate of $6^{\circ}$ per minute.

The average grain size is determined using Scherer formula [52]

$$
L=\frac{0.94 \lambda}{\beta_{1 / 2} \cos \theta},
$$

where $\lambda=1.54 \AA$, CuK $\alpha 1$ wavelength, $\beta_{1 / 2}=$ full width of a diffraction line at one half of maximum intensity (FWHM) in radian.

3.2.3. Band Gap Analysis. To find the wavelength of light needed for the excitation of $\mathrm{TiO}_{2}$ photocatalyst, it is very important to find the band gap [53]. The $\mathrm{TiO}_{2}$ samples were analyzed in the diffused reflectance mode of PerkinElmer, LAMBDA $35 \mathrm{UV} / \mathrm{Vis}$ spectrophotometer.

When photons having energy greater than or equal to the band gap are absorbed by a semiconductor, an electron from the valance band jumps to the conduction band, and depending on the band gap energy there occurs a rise in the absorbency of the semiconductor. The relation between the absorption coefficient $(\alpha)$ and the energy of the incidental photon depends on the type of electronic transition [54]. There are two types of transition.

(i) Direct transition-when the electron momentum is conserved.

(ii) Indirect transition-when the momentum of electron is not conserved.

The electronic properties of the synthesized pure and metal doped $\mathrm{TiO}_{2}$ were analyzed using the remission function of Kubelka-Munk, $F\left(R_{\infty}\right)[54,55]$

$$
F\left(R_{\infty}\right)=\frac{\left(1-R_{\infty}\right)}{2 R_{\infty}}=\frac{\alpha}{S},
$$

where $R_{\infty}$ is the diffuse reflectance (of a given wavelength), of a dense layer of nontransparent infinite material and is given by.

$$
R_{\infty}=\frac{\left(R_{\text {sample }}\right)}{R_{\text {standard }}}
$$

and $\alpha$ and $S$ are the absorption coefficient $\left(\mathrm{cm}^{-1}\right)$ and dispersion factor, respectively. For particle larger than $5 \mu \mathrm{m}$, $S$ is independent of the wavelength. $\alpha$ is related to the energy of incident proton by the following equation [54]:

$$
\alpha=A\left(E-E_{g}\right)^{\gamma},
$$

where $A$ is a constant and depends on material properties, $E$ is energy of photon, $E_{g}$ the band gap, and $\gamma$ is a constant, and depending on the type of electronic transition it can take different values as $[54,56]$.

$$
\begin{aligned}
& \gamma=1 / 2-\text { permitted direct transition. } \\
& \gamma=2 \text { - permitted indirect transition. } \\
& \gamma=3 / 2 \text { - prohibited direct transition. } \\
& \gamma=3 \text {-prohibited indirect transition. }
\end{aligned}
$$

Therefore,

$$
\begin{aligned}
& F\left(R_{\infty}\right)=\frac{\alpha}{S}=A \frac{\left(E-E_{g}\right)^{\gamma}}{S}, \\
& E(\mathrm{eV})=\frac{h c}{\lambda(\mathrm{nm})}=\frac{1236}{\lambda(\mathrm{nm})},
\end{aligned}
$$

where $h$ is plank's constant and $c$ is speed of light. In case of direct transition, the equation is

$$
F\left(R_{\infty}\right)^{2}=\left(\frac{A}{S}\right)^{2}=\left(E-E_{g}\right),
$$

while for an indirect transition the equation takes the following form:

$$
F\left(R_{\infty}\right)^{1 / 2}=\left(\frac{A}{S}\right)^{1 / 2}=\left(E-E_{g}\right) .
$$

The plot of $F\left(R_{\infty}\right)^{1 / 2}$ versus $E(\mathrm{eV})$ gives the indirect transition while the direct transitions are obtained by plotting $F\left(R_{\infty}\right)^{2}$ versus $E(\mathrm{eV})$.

\subsection{Batch Studies}

3.3.1. Removal Efficiency. The removal efficiencies of pure and metal-doped titania were calculated using the following formula:

$$
E=\frac{C_{o}-C_{f}}{C_{o}} \times 100 \%,
$$

where $C_{o}$ and $C_{f}$ are the initial and final equilibrium concentration of As(III) (mg/L) in the solution.

For each sample $100 \mathrm{~mL}$ of $0.5 \mathrm{mg} / \mathrm{L}$ of As(III), solution was prepared from the stock and transferred into a $250 \mathrm{~mL}$ volumetric flask. An amount of $0.5 \mathrm{~g}$ of the respective pure or metal-doped titania nanoparticles was added to it and the flask was placed on an orbital shaker at $145 \mathrm{rpm}$ for 60 minutes for the equilibrium to be reached, centrifuged at $4000 \mathrm{rpm}$, and finally analyzed.

3.3.2. Effect of $p H$ on Removal Efficiency. The above process was repeated at different $\mathrm{pH}$ values $(4,7$, and 10$)$ and removal efficiency at each $\mathrm{pH}$ was calculated.

3.3.3. Batch Adsorption Studies. For adsorption studies, $100 \mathrm{~mL}$ of As(III) solution of different concentrations $(0.1,0.2$, $0.4,0.8,1.5,3$, and $6 \mathrm{ppm}$ ) wastaken in a $250 \mathrm{~mL}$ volumetric flasks. An amount of $0.35 \mathrm{~g}$ of the concerned nanoparticles was added to it, placed on an orbital shaker at $145 \mathrm{rpm}$ for 90 minutes, and centrifuged at $4000 \mathrm{rpm}$. They were then analyzed with atomic absorption spectrophotometer (AAS vario 6, Analytik Jena (Germany)). 
3.3.4. Batch Kinetic Studies. The kinetic studies were performed using 1 liter volumetric flasks. An amount of $500 \mathrm{~mL}$ of $0.5 \mathrm{ppm} \mathrm{As}(\mathrm{III})$ was taken in it, $0.5 \mathrm{~g}$ of pure titania nanoparticles was added to the flask and then placed on an orbital shaker at $145 \mathrm{rpm}$, and $5 \mathrm{~mL}$ of solution was taken out from the flask after specific time $(1,3,6,9,12,15,20,30,40$, $50,60,70,80$, and 90 minutes), centrifuged at $4000 \mathrm{rpm}$, and finally analyzed.

The same process was repeated for the doped titania nanoparticles as well.

The amount of As(III) adsorbed $\left(q_{t}\right)$ was calculated using the following formula:

$$
q_{t}=\frac{\left(C_{o}-C_{t}\right) V}{m}
$$

where $C_{o}$ and $C_{t}$ are the initial $\mathrm{As}(\mathrm{III})(\mathrm{mg} / \mathrm{L})$ concentration and the As(III) concentration after the time interval $t$, respectively, $V$ is the volume of $\mathrm{As}$ (III) (L) and $m$ is the mass (g) of the nanoparticles.

\subsection{Glass Beads Coating}

3.4.1. Glass Beads Etching. Etching of the glass beads was done using HF. In this method, the glass beads were dipped in a $10 \%$ HF solution in a covered polyethylene bottle for 24 hours, and they were then removed from the solution and rinsed with water to remove any traces of HF left.

3.4.2. Coating. Glass beads were coated with nanoparticles using heat attachment method; $5 \mathrm{~g}$ of titania nanoparticles was dissolved in $100-200 \mathrm{~mL}$ water in a $250 \mathrm{~mL}$ titration flask and placed on a shaker at $150 \mathrm{rpm}$ for 15 minutes; 200 grams of etched glass beads were weighed and transferred to the titania suspension, and this was kept on shaking for one hour. The glass beads were then transferred to a Petri dish and were dipped in the titania suspension and dried in oven at $105^{\circ} \mathrm{C}$. The glass beads were then carefully removed from the Petri dish, transferred to a china dish, and placed in furnace at $600^{\circ} \mathrm{C}$ for about 2 hours. The coated glass beads were then cooled, washed with distilled water till none of the nanoparticles attached to the surface gets detached with water, dried in oven at $105^{\circ} \mathrm{C}$, and finally transferred to a plastic bottle and kept in dark.

The metal-doped titania nanoparticles were also coated on the glass beads using the same procedure.

3.5. Column Studies. Ordinary $100 \mathrm{~mL}$ Burette was used for the preparation of columns, with a diameter of $1.5 \mathrm{~cm}$ and height of 2 feet. The bottoms of the columns were plugged in with folded aluminum foil just to make a support for the glass beads. Cotton wool or glass wool was not used due to possibility of clogging by the nanoparticles. The columns were packed with the desired nanoparticles coated glass beads to the height needed by weighing the glass beads and then packing them in the columns. The column was then operated

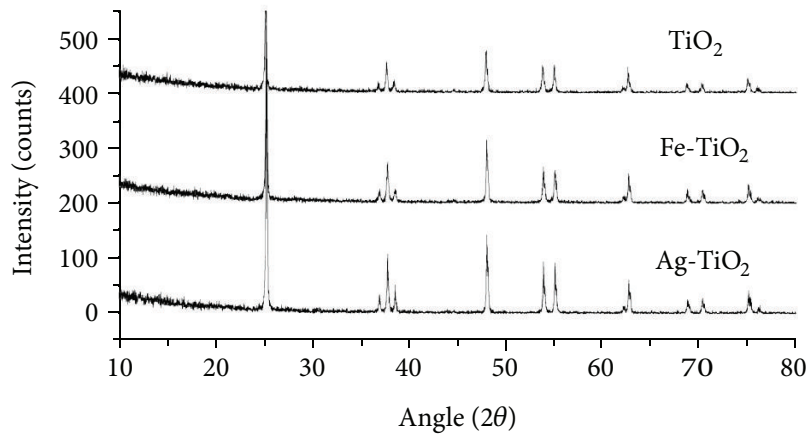

FIGURE 1: XRD patterns of pure and metal-doped titania nanoparticles.

in such-manner that a calculated amount of arsenic stock solution was constantly added to it through a graduated cylinder and allowing it to flow along gravity with a constant rate. The rate of flow was constantly checked by measuring the amount flowing per minute after every ten minutes. Once the process started, samples were collected at regular interval using plastic bottles. This process was continued till column exhaustion and the amount of arsenic in different samples was analyzed. From these results "Breakthrough curves" were drawn. Thomas and Yoon-Nelson models were applied to predict the breakthrough curves and to find the characteristic column parameters useful for process design.

3.6. Column Regeneration. When the column was fully exhausted after lengthy column runs, it was regenerated using $10 \% \mathrm{w} / \mathrm{v} \mathrm{NaOH}$ solution. Sufficient amount of the regeneration (10 bed volumes) was passed through the column at a very slow flow rate $(0.5 \mathrm{~mL} / \mathrm{min})$. The column was then rinsed thoroughly with mild warm deionized water at a flow rate of $2 \mathrm{~mL} / \mathrm{min}$ for about 10 bed volumes.

\section{Results and Discussion}

4.1. Crystal Phase Composition of the Nanoparticles. X-ray Diffraction was used to determine the crystal phase composition and the crystallite size of pure and metal-doped titania nanoparticles. It is shown by the XRD analysis that the titania nanoparticles are $100 \%$ in anatase form. No rutile traces were seen in the XRD patterns. The crystalline sizes of the nanoparticles (as calculated from Shrerrer formula) were in the range of 30 to $40 \mathrm{~nm}$ (titania $(33.83 \mathrm{~nm}), \mathrm{Ag}-\mathrm{TiO}_{2}$ $(34.28 \mathrm{~nm})$, and $\left.\mathrm{Fe}-\mathrm{TiO}_{2}(37.02 \mathrm{~nm})\right)$. The XRD patterns are given in Figure 1.

4.2. S.E.M. Results. Particle size and morphology were observed using S.E.M as shown in Figure 2. It is clear from the figure that samples consisted of fine particles. The surface morphology of the three types of nanoparticles shows some variation. The particles were mostly spheroid and loosed. Macropores are also clearly visible in the S.E.M images. 


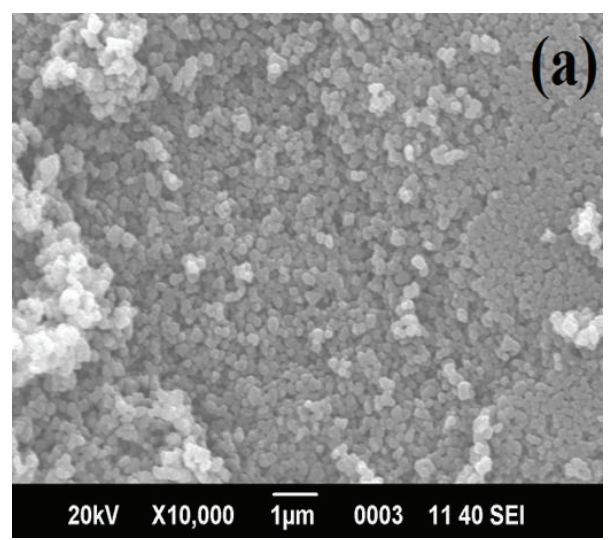

(a)

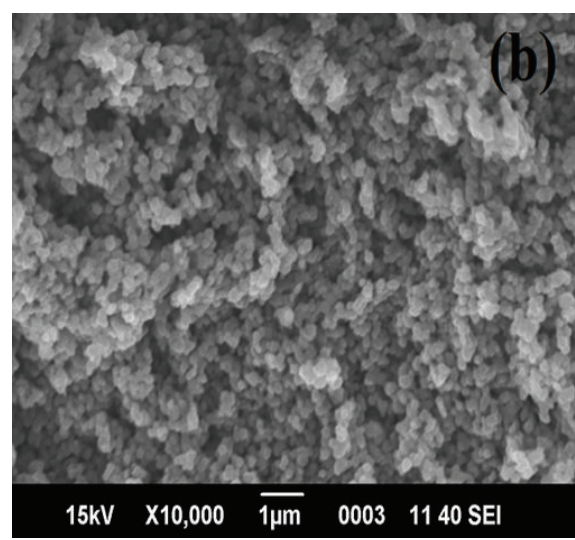

(b)

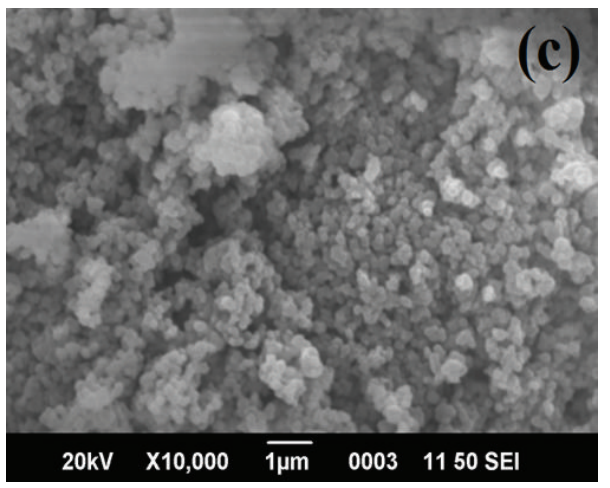

(c)

FIGURE 2: S.E.M. micrographs of pure and metal-doped titania nanoparticles. (a) $\mathrm{TiO}_{2}$, (b) $\mathrm{Ag}-\mathrm{TiO}_{2}$, and (c) $\mathrm{Fe}-\mathrm{TiO}_{2}$.

TABLE 1: Direct and indirect band gap values of pure and metaldoped titania nanoparticles.

\begin{tabular}{lcc}
\hline Nanoparticles & Direct & Band Gap \\
& 3.27 & Indirect \\
\hline $\mathrm{TiO}_{2}$ & 3.25 & 3.2 \\
$\mathrm{Ag}_{-}-\mathrm{TiO}_{2}$ & 3.27 & 2.95 \\
$\mathrm{Fe}-\mathrm{TiO}_{2}$ & 2.82 \\
\hline
\end{tabular}

TABLE 2: Removal efficiencies of different nanoparticles used.

\begin{tabular}{lccc}
\hline Nanoparticles & $\mathrm{TiO}_{2}$ & $\mathrm{Ag}-\mathrm{TiO}_{2}$ & $\mathrm{Fe}-\mathrm{TiO}_{2}$ \\
\hline Removal efficiency (\%) & 65 & 90 & 96 \\
\hline
\end{tabular}

4.3. Band Gap Analysis. The band gaps for pure and metaldoped titania nanoparticles were determined by using (6) for direct transitions, given as follows:

$$
F\left(R_{\infty}\right)^{2}=\left(\frac{A}{S}\right)^{2}=\left(E-E_{g}\right) .
$$

The plot of $F\left(R_{\infty}\right)^{2}$ versus $E(\mathrm{eV})$ gives the direct transitions for the pure and metal-doped titania. The plots are given in Figure 3. By extrapolating the linear part of the graphs the band gap $\left(E_{g}\right)$ is obtained, as shown in the figure.
However, for an indirect transition, (7) is used as follows:

$$
F\left(R_{\infty}\right)^{1 / 2}=\left(\frac{A}{S}\right)^{1 / 2}=\left(E-E_{g}\right) .
$$

The plot of $F\left(R_{\infty}\right)^{1 / 2}$ versus $E(\mathrm{eV})$ gives the indirect transitions for the pure and metal-doped titania. The plots are given in Figure 4. By extrapolating the linear part of the plots the band gap $\left(E_{q}\right)$ is obtained, as shown in the figure.

The band gap of $\mathrm{TiO}_{2}$ reported in the literature is $3.2 \mathrm{eV}$, which corresponds to a wavelength of $385 \mathrm{~nm}$. For the synthesized pure titania nanoparticles, the direct transition (Figure 3) shows unrealistic value of band gap above 3.27, which for anatase phase is not expected. Similarly some unexpected band gap values were obtained for the metaldoped titania nanoparticles as well (as shown in Table 1). The indirect transitions (Figure 4) show the band gap values of $3.2 \mathrm{eV}, 2.95 \mathrm{eV}$, and $2.82 \mathrm{eV}$ for pure $\mathrm{TiO}_{2}, \mathrm{Ag}-\mathrm{TiO}_{2}$, and $\mathrm{Fe}-\mathrm{TiO}_{2}$ nanoparticles, respectively, and corresponds to wavelengths of $385 \mathrm{~nm}, 420 \mathrm{~nm}$, and $440 \mathrm{~nm}$, respectively. Therefore, the synthesized pure and metal-doped titania nanoparticles follow indirect type transitions [54].

4.4. Removal Efficiency. The removal efficiencies of pure and metal-doped titania nanoparticles are shown in the Table 2. It is clear from the table that due to metal doping the removal efficiency of Titania has increased enormously. 
TABLE 3: Langmuir and Freundlich isotherm parameters of As(III) adsorption for pure and metal-doped titania.

\begin{tabular}{lcccccc}
\hline \multirow{2}{*}{ Nanoparticles } & \multicolumn{3}{c}{ Langmuir isotherm parameters } & \multicolumn{3}{c}{ Freundlich isotherm parameters } \\
& $q_{m}$ & $b$ & $R_{L}^{*}$ & $R^{2}$ & $n$ & $K_{f}$ \\
\hline $\mathrm{TiO}_{2}$ & 1.6 & 0.377 & 0.84 & 0.978 & 1.22 & 0.385 \\
$\mathrm{Ag}-\mathrm{TiO}_{2}$ & 1.71 & 0.94 & 0.68 & 0.988 & 1.32 & 0.996 \\
$\mathrm{Fe}-\mathrm{TiO}_{2}$ & 3.08 & 2.305 & 0.46 & 0.985 & 1.21 & 0.990 \\
\hline
\end{tabular}

${ }^{*}$ For $C_{o}=0.5 \mathrm{ppm}$.

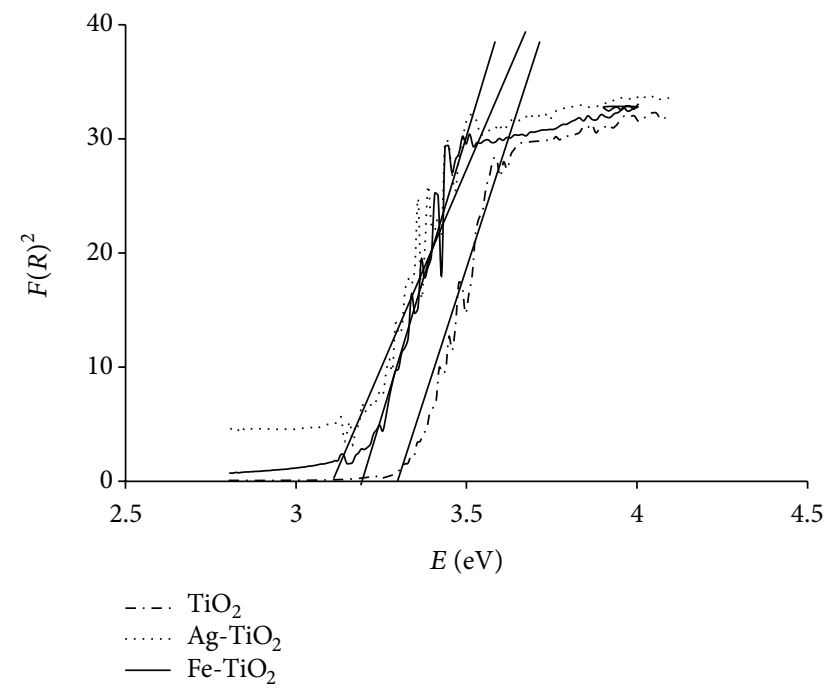

FIGURE 3: Diffused reflectance spectra for direct transition of pure and metal-doped titania nanoparticles.

The main reason is that metal doping has shifted the absorption band of titania from UV region into the visible region of the spectrum, thereby increasing its photocatalytic and adsorption efficiency compared to that of pure titania.

4.5. Effect of $p H$. The removal efficiencies were measured at three different $\mathrm{pH}$ values of 4, 7, and 10, as shown in Figure 5.

It is clear from the figure that as we approach the neutral $\mathrm{pH}$ the removal efficiency increases. The removal efficiency decreases on moving both to acidic and basic $\mathrm{pH}$. The decrease in removal efficiency is more in basic region than the acidic.

Thus from this point forward, all the processes are carried out at neutral $\mathrm{pH}$, that is, $\mathrm{pH} 7 \pm 0.1$.

4.6. Adsorption Isotherms. Adsorption studies were carried out to determine the suitable conditions for maximum arsenic removal by the nanoparticles. The $\mathrm{pH}$ of the solutions was adjusted at 7. Langmuir and Freundlich models were applied for adsorption studies.

The Langmuir isotherm assumes monolayer adsorption at the adsorbent surface. The linear form of Langmuir adsorption isotherm equation is as follows [57]:

$$
\frac{C_{e}}{q_{e}}=\frac{C_{e}}{q_{m}}+\frac{1}{q_{m} b},
$$

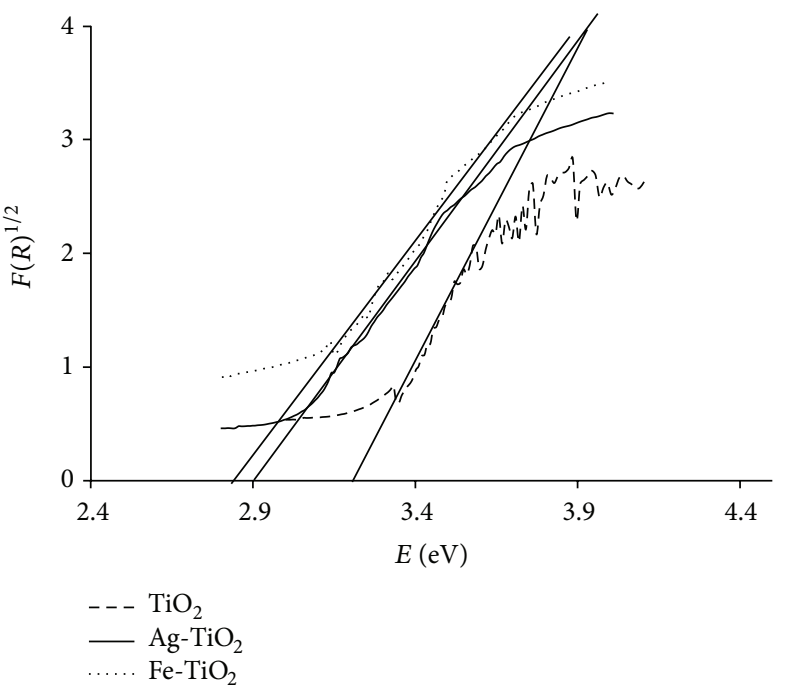

FIGURE 4: Diffused reflectance spectra for indirect transition of pure and metal-doped titania nanoparticles.

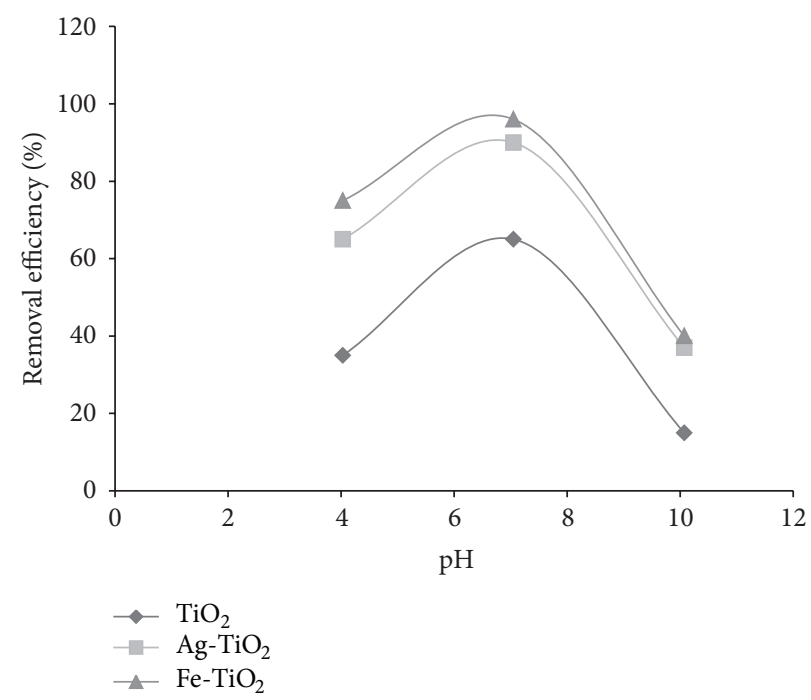

Figure 5: Effect of pH on removal efficiency.

where $q_{e}$ is the quantity of $\mathrm{As}(\mathrm{III})$ adsorbed per unit weight of nanoparticles $(\mathrm{mg} / \mathrm{g})$ at equilibrium, and $C_{e}$ is the equilibrium As(III) concentration in the solution after adsorption. $q_{m}$ and $b$ are Langmuir constants corresponding to maximum adsorption at monolayer coverage $(\mathrm{mg} / \mathrm{g})$ 


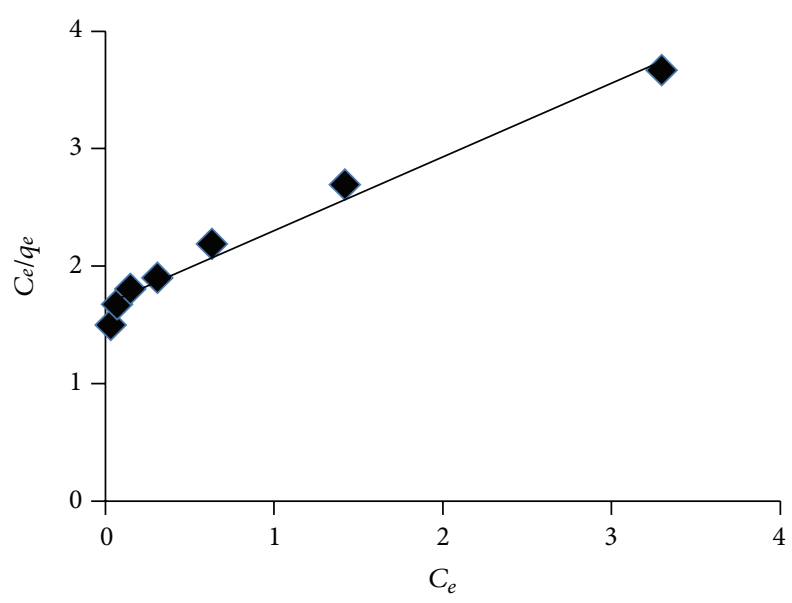

(a)

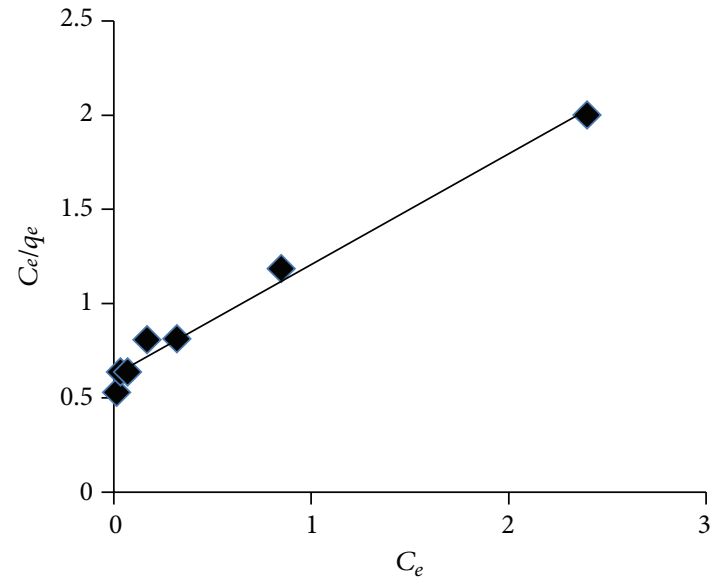

(b)

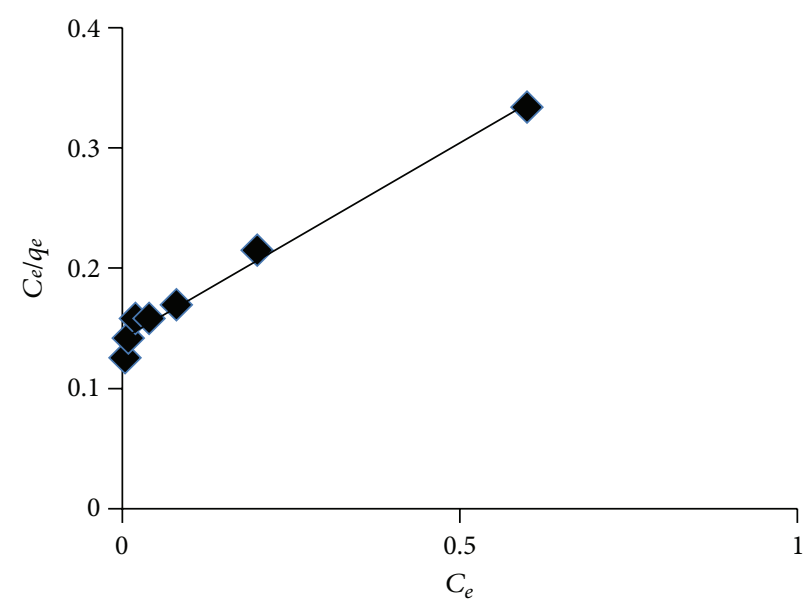

(c)

Figure 6: Langmuir adsorption isotherms. (a) $\mathrm{TiO}_{2}$, (b) $\mathrm{Ag}-\mathrm{TiO}_{2}$, and (c) $\mathrm{Fe}-\mathrm{TiO}_{2}$.

and energy of dsorption respectively. The values of $q_{m}$ and $b$ can be obtained from the slope and intercept of the curves, Figure 6.

The value of $b$ can be represented by another dimensionless quantity $R_{L}$ given by the following equation [58]:

$$
R_{L}=\frac{1}{1+\left(b C_{o}\right)},
$$

where $C_{o}$ is the initial arsenic concentration, and the value of $R_{L}$ gives knowledge about the isotherm to be irreversible $\left(R_{L}=0\right)$, favorable $\left(0<R_{L}<1\right)$, linear $\left(R_{L}=1\right)$, or unfavorable $\left(R_{L}>1\right)$ [53]. The values of all the different constants obtained are given in Table 2 . These values clearly suggest that Langmuir isotherm gives a good fit to the experimental results. Moreover, the value of constant $b$ for the different nanoparticles also shows great affinity of the binding sites and chemical interaction between the adsorbent and adsorbate. The value of $R_{L}$ for all the four nanoparticles lies between 0 and 1 suggesting favorable adsorption of As(III) by pure and metal-doped titania.
The Freundlich isotherm equation is generally given by $[59,60]$ :

$$
q_{e}=K_{f} \times C_{e}^{1 / n},
$$

where $C_{e}$ is the amount of As(III) left in the solution after adsorption and $q_{e}$ is the amount of As(III) adsorbed per unit weight of the adsorbent $(\mathrm{mg} / \mathrm{g}) . K_{f}$ and $n$ are Freundlich constants. The linear form of Freundlich equation in logarithmic form is given as follows:

$$
\ln q=\ln K_{f}+n \ln C_{e} .
$$

The plot of $\ln C_{e}$ versus $\ln q_{e}$ at various initial concentration of $\mathrm{As}$ (III) (0.1, 0.2, 0.4, 0.8, 1.5, 3, and $6 \mathrm{ppm})$ was drawn and each gave a straight line with slope equal to $n$ and intercept equal to $\ln K_{f}$, Figure 7. The values of different parameters obtained from the plots are given in Table 3 . The higher the value of $K_{f}$ represents higher affinity of the adsorbent for As(III), while the value of $n$ between 1 and 10 shows favorable adsorption. It is clear from the table that the value of $n$ for all the four nanoparticles is above 1 , showing that the adsorption 


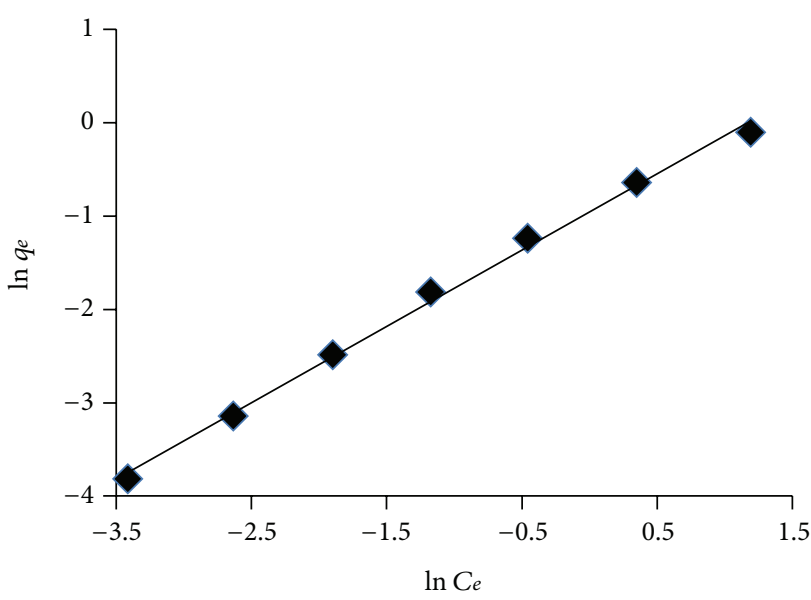

(a)

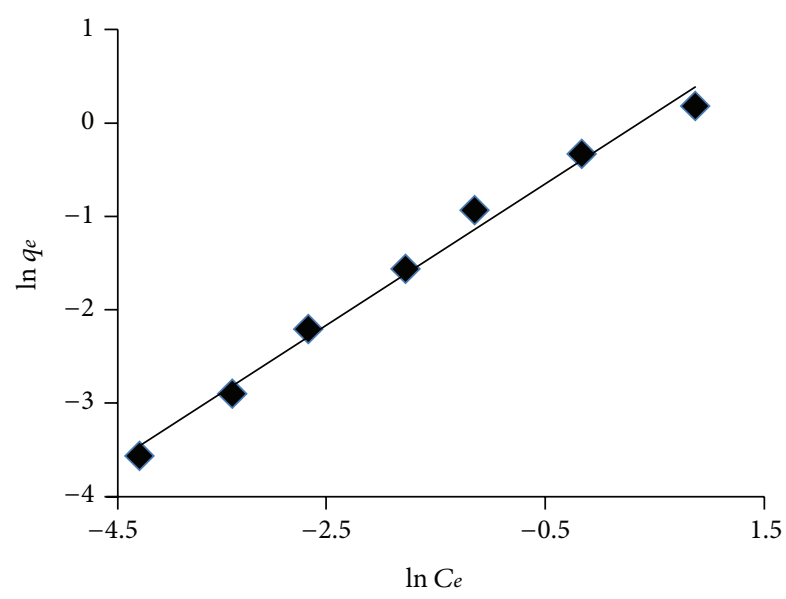

(b)

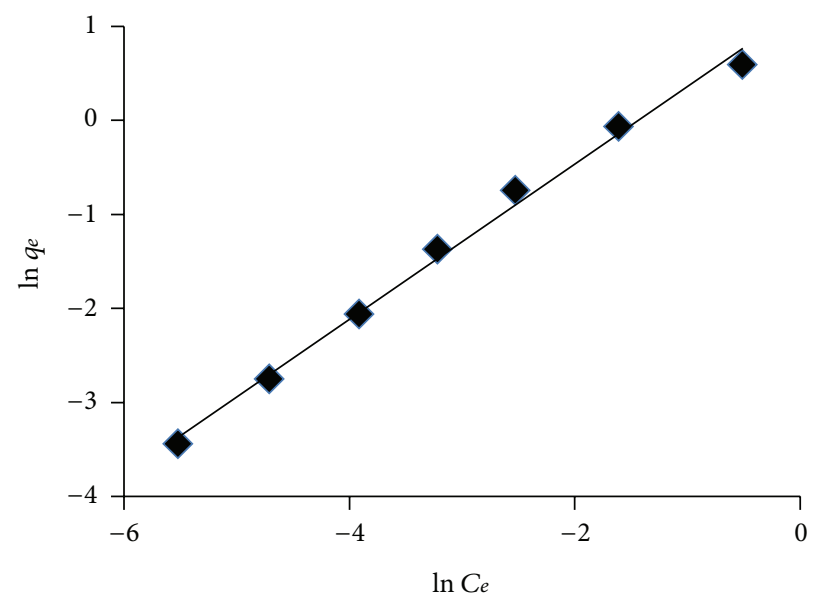

(c)

Figure 7: Freundlich adsorption isotherms. (a) $\mathrm{TiO}_{2}$, (b) $\mathrm{Ag}-\mathrm{TiO}_{2}$, and (c) $\mathrm{Fe}-\mathrm{TiO}_{2}$.

process is favorable. From the table, it can be seen that the value of $K_{f}$ for metal-doped titania are higher than pure titania. Moreover, the value of $K_{f}$ for Fe-doped titania is the greatest showing that among the metal-doped titania Fedoped titania serves the purpose well. The value of $R^{2}$ for all the nanoparticles is also above 0.98 , showing strong linear relationship between $\ln q_{e}$ and $\ln C_{e}$.

4.7. Kinetic Isotherms. Several models are available to express the mechanism of adsorption of solute onto the sorbent. To investigate the mechanism of adsorption, both Lagergren and pseudo-second-order equation were used.

To apply the Lagergren equation, an initial As(III) solution of $0.5 \mathrm{ppm}(500 \mathrm{~mL})$ was taken in a $1 \mathrm{~L}$ flask and $0.5 \mathrm{~g}$ of pure titania nanoparticles were added to it and placed on an orbital shaker at $145 \mathrm{rpm}, 5 \mathrm{~mL}$ of solution was taken out from the flask after specific time $(1,3,6,9,12,15,20,30,40,50,60$, $70,80,90,120$, and 150 minutes), centrifuged at $4000 \mathrm{rpm}$ and finally analyzed. The kinetic data for this system is shown in Figure 8.

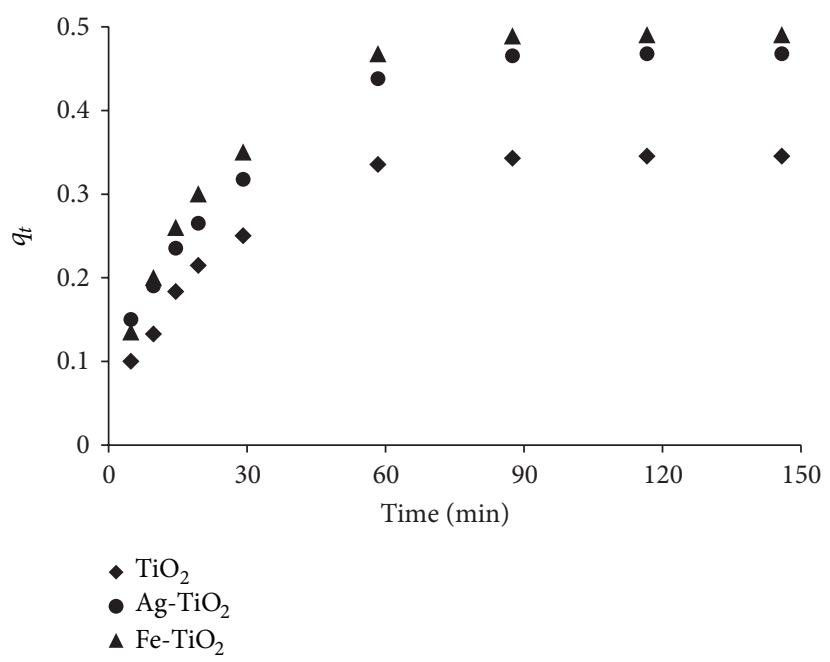

FIgURE 8: Experimental curve for arsenic adsorption by pure and metal-doped titania nanoparticles. 


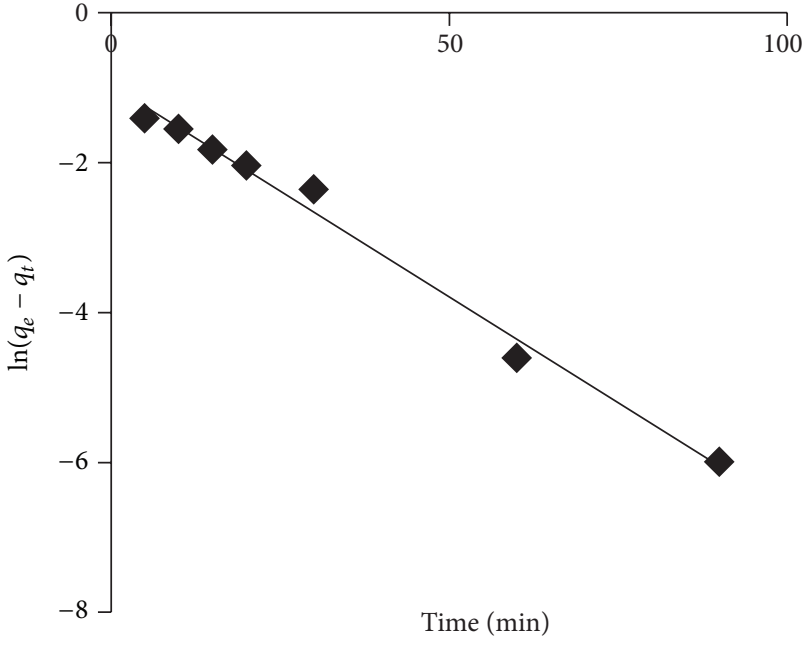

(a)

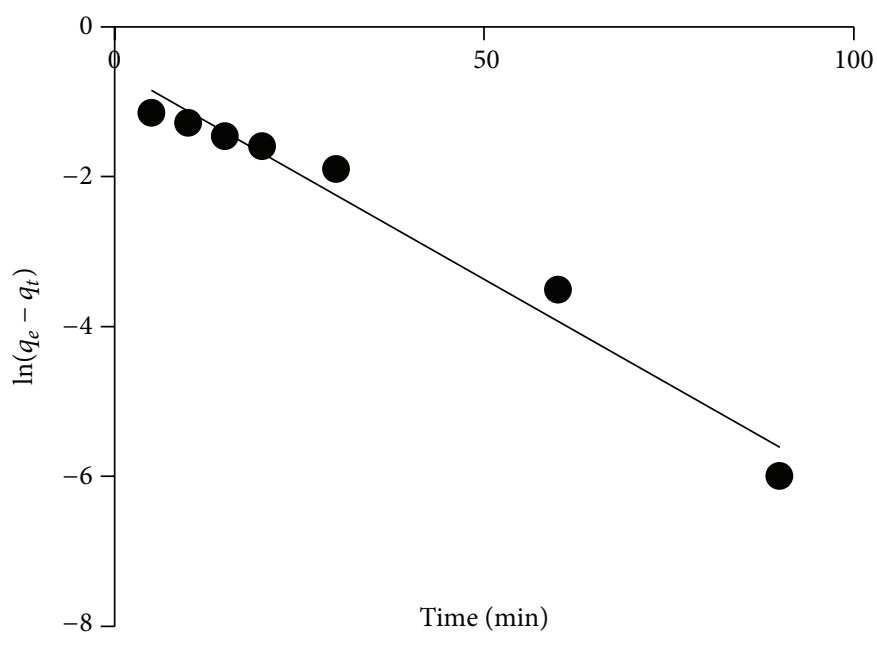

(b)

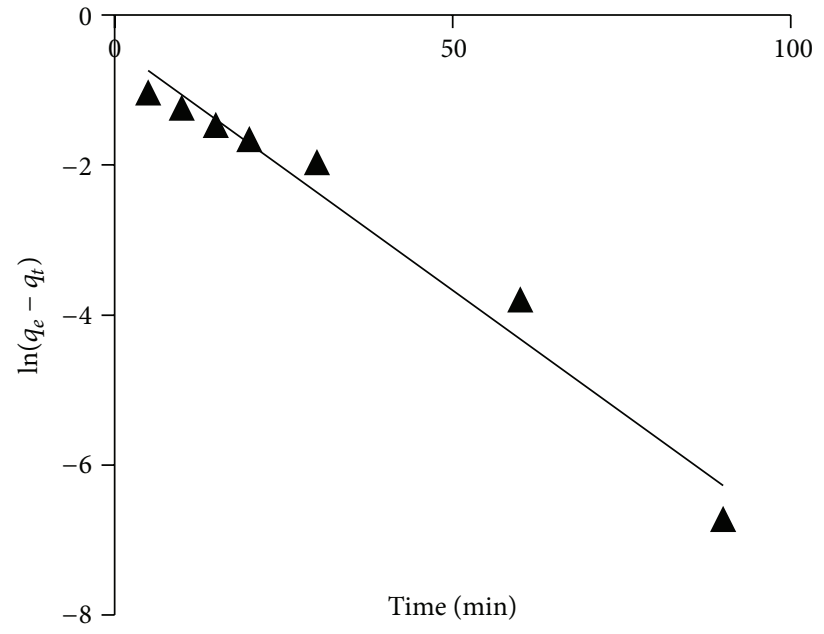

(c)

Figure 9: The kinetic data in Figure 8 plotted according to (18). (a) $\mathrm{TiO}_{2}$, (b) $\mathrm{Ag}-\mathrm{TiO}_{2}$, and (c) $\mathrm{Fe}-\mathrm{TiO}_{2}$.

The Lagergren rate equation [61] is given as follows:

$$
\frac{d q_{t}}{d t}=k_{L}\left(q_{e}-q_{t}\right)
$$

where $q_{t}$ and $q_{e}$ are sorbed amount at any time $t$ and equilibrium sorbed concentration, respectively. $k_{L}$ is the Lagergren rate constant. At an initial condition of $q_{t}=0$ at time $t=0$, (16) takes the following form:

$$
q_{t}=q_{e}\left[1-\exp \left(-k_{L} t\right)\right] .
$$

Rearranging (17), we get

$$
\ln \left(q_{e}-q_{t}\right)=\ln q_{e}-k_{L} t .
$$

In the above equation, $q_{e}$ and $k_{L}$ are fitting parameters. We need to have the value of $q_{e}$ in order to find the left side of (18). The logarithmic term $\ln \left(q_{e}-q_{t}\right)$ indicates that $q_{e}$ is given a maximum measured value. From the data plotted in Figure 8, the maximum value is shown by the second last data point
TABLE 4: Lagergren equation parameters for As(III) adsorption on pure and metal-doped titania nanoparticles.

\begin{tabular}{lccc}
\hline Nanoparticles & $q_{e}$ & $k_{L}$ & $R^{2}$ \\
\hline $\mathrm{TiO}_{2}$ & 0.38 & 0.056 & 0.989 \\
$\mathrm{Ag}-\mathrm{TiO}_{2}$ & 0.564 & 0.056 & 0.969 \\
$\mathrm{Fe}_{2}-\mathrm{TiO}_{2}$ & 0.66 & 0.065 & 0.97 \\
\hline
\end{tabular}

measured at $120 \mathrm{~min}$. The term $q_{e}$ on the left hand side of (18) was given the value at this data point. So for pure titania $q_{e}=0.345 \mathrm{mg} / \mathrm{g}$, for Silver-doped titania $q_{e}=0.475 \mathrm{mg} / \mathrm{g}$ and for iron-doped titania $q_{e}=0.49 \mathrm{mg} / \mathrm{g}$. The data in Figure 8, plotted according to (18), is shown in Figure 9.

It is clear from the value of $R^{2}$ that the linear fit is satisfactory. The values of $q_{e}$ and $k_{L}$ were calculated from the intercept and slope of the linear plot. The values of various parameters derived are listed in figure in Table 4. 
TABLE 5: Pseudo-second-order rate parameters for As(III) adsorption on pure and metal-doped titania nanoparticles.

\begin{tabular}{lcccc}
\hline Nanoparticles & $q_{e}(\mathrm{mg} / \mathrm{g})$ & $k(\mathrm{~g} / \mathrm{mg} \mathrm{min})$ & $h(\mathrm{mg} / \mathrm{g} \mathrm{min})$ & $R^{2}$ \\
\hline $\mathrm{TiO}_{2}$ & 0.42 & 0.14 & 0.024 & 0.992 \\
$\mathrm{Ag}^{-} \mathrm{TiO}_{2}$ & 0.56 & 0.097 & 0.03 & 0.986 \\
$\mathrm{Fe}_{-}-\mathrm{TiO}_{2}$ & 0.59 & 0.102 & 0.035 & 0.995 \\
\hline
\end{tabular}

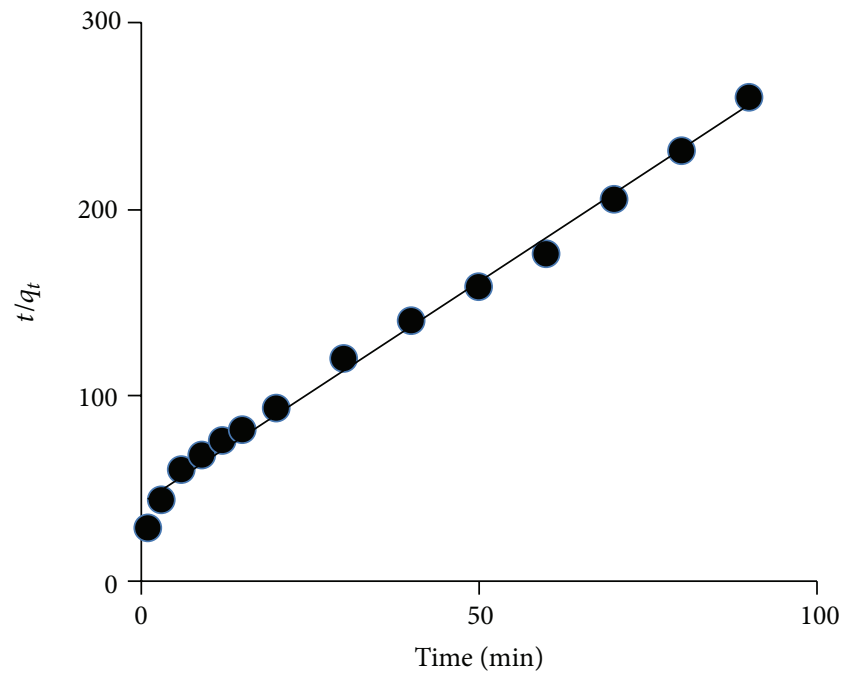

(a)

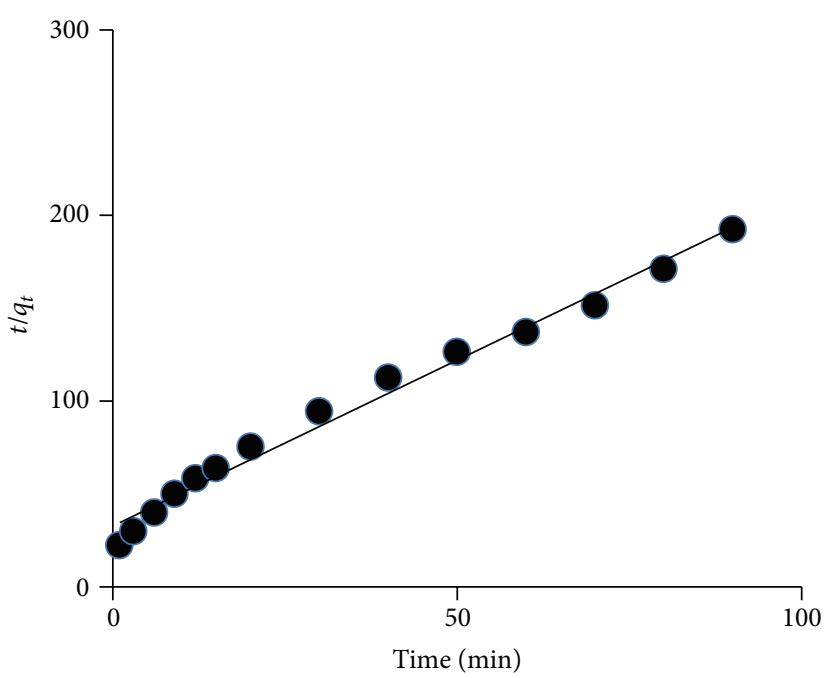

(b)

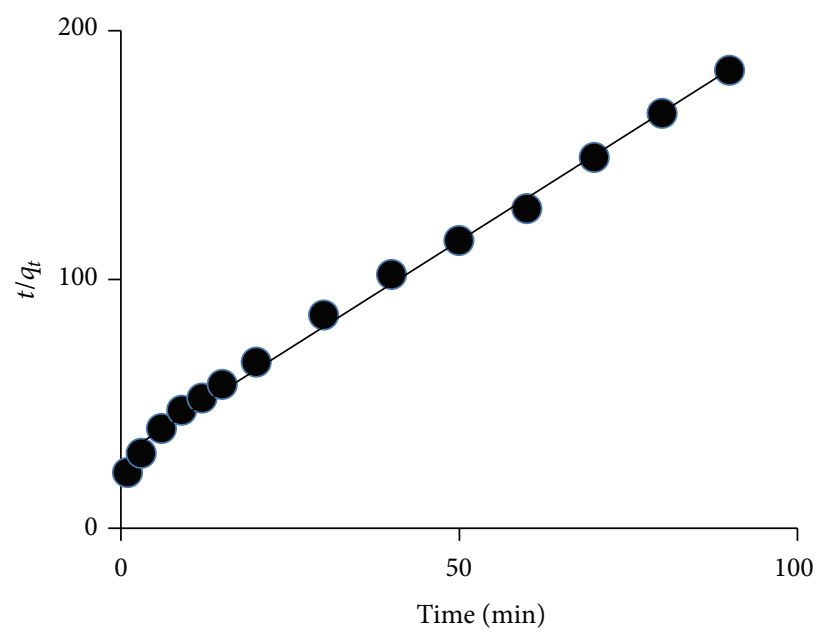

(c)

Figure 10: Pseudo-second-order kinetic model. (a) $\mathrm{TiO}_{2}$, (b) $\mathrm{Ag}-\mathrm{TiO}_{2}$, and (c) $\mathrm{Fe}-\mathrm{TiO}_{2}$.

TABLE 6: Thomas model parameters for different nanoparticles coated glass beads.

\begin{tabular}{lccc}
\hline Nanoparticles & $\mathrm{TiO}_{2}$ & $\mathrm{Ag}-\mathrm{TiO}_{2}$ & $\mathrm{Fe}-\mathrm{TiO}_{2}$ \\
\hline$K_{T}$ & 0.2 & 0.2 & 0.2 \\
$q_{o}$ & 0.53 & 0.6 & 0.61 \\
\hline
\end{tabular}
[62]

The pseudo-second-order kinetic equation is given as

$$
\frac{d q_{t}}{d t}=k\left(q_{e}-q_{t}\right)^{2}
$$

where $q_{e}$ and $q_{t}$ are the sorption capacities (mg/g) at equilibrium and time $t$, respectively, and $k$ is the pseudo-secondorder rate constant $\left(\mathrm{g} \mathrm{mg}^{-1} \mathrm{~min}^{-1}\right)$. At boundary conditions, $t=0$ to $t$ and $q_{t}=0$ to $q_{t}$, the integrated form of (19) is given as [63]

$$
\frac{1}{\left(q_{e}-q_{t}\right)}=\frac{1}{q_{e}}+k t .
$$

Rearranging this equation, we get

$$
q_{t}=\frac{1}{\left(1 / k q_{e}^{2}\right)+\left(t / q_{e}\right)} .
$$




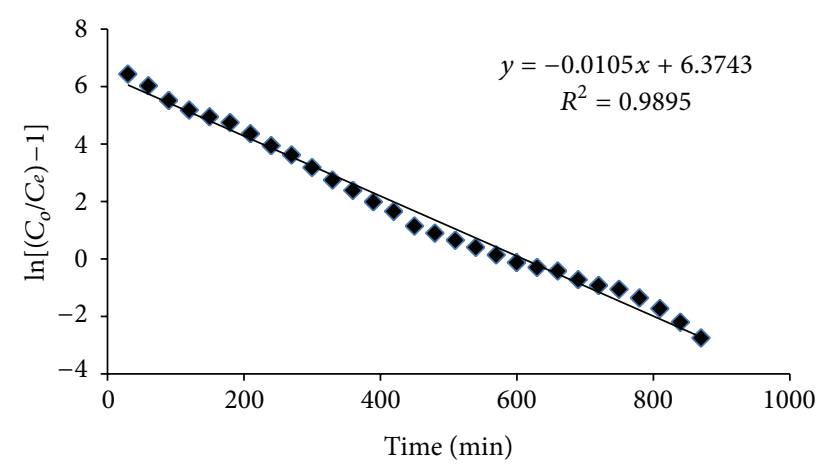

FIgURE 11: Plot of time $(t)$ versus $\ln \left(\left(C_{o} / C_{e}\right)-1\right)$.

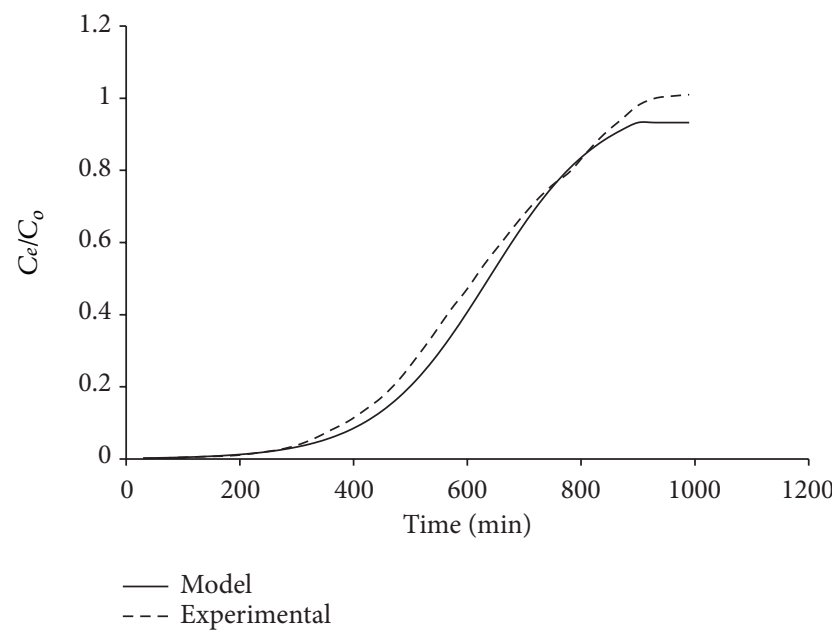

FIGURE 12: Thomas model, comparison of experimental and predicted breakthrough curves.

This gets the linear form as

$$
\frac{t}{q_{t}}=\frac{1}{k q_{e}^{2}}+\frac{1}{q_{e}} t
$$

where $h$ can be regarded as the initial adsorption rate as $q_{t} / t \rightarrow 0$, and hence

$$
h=k q_{e}^{2}
$$

Equation (22) takes the form as

$$
\frac{t}{q_{t}}=\frac{1}{h}+\frac{1}{q_{e}} t .
$$

Thus plotting $t / q_{t}$ versus $t$ will give a straight line, as shown in Figure 10. The value of $q_{e}, k$, and $h$ can be determined from the slope and intercept of the plot. The values of different parameters obtained are given in Table 5 .

\subsection{Column Studies}

4.8.1. Adsorption Column Process. In the beginning, all the As(III) was adsorbed by the column which resulted in zero effluent concentration. As more and more influent was passed through the column, a gradual rise in the effluent concentration was observed. In the down flow mode, when the As(III) bearing water was introduced at the top of the column, most of the As(III) adsorption first occurs in the first few centimeters of the column, called the adsorption zone. As the process continues, the upper few centimeters of the column became saturated with the influent and the adsorption zone moves down through the column. Finally, the adsorption zone reaches the bottom of the column and As(III) concentration in the effluent rises.

By plotting As(III) concentration $(\mathrm{mg} / \mathrm{L})$ in the effluent against time (hrs), a breakthrough curve is obtained. On the breakthrough curve, the point at which the effluent As(III) concentration reaches its maximum permissible limit $(0.01 \mathrm{mg} / \mathrm{L})$ is called the column breakthrough point and the corresponding time (hrs) as the breakthrough time. The point at which the effluent As(III) concentration reaches 90\% of the influent concentration is known as column exhaustion point and the corresponding time (hrs) as exhaustion time.

Thomas and Yoon-Nelson models were applied for column design. Effects of different column parameters on the breakthrough and exhaustion time of column were found. The titania nanoparticles leaching from the $10 \mathrm{~cm}$ column during the adsorption studies were very small, $0.015 \mathrm{mg} / \mathrm{L}$.

4.8.2. Thomas Model. A successful design of column adsorption procedure needs prediction of the concentration-time profile or breakthrough curve for the effluent. The maximum adsorption capacity of an adsorbent is also required in design. The Thomas model generally serves the purpose well. Thomas model has the following form $[64,65]$ :

$$
\frac{C_{e}}{C_{o}}=\frac{1}{1+\exp \left[K_{T}\left(q_{o} m-C_{o} V\right) / \theta\right]},
$$

where $K_{T}$ is the Thomas rate constant ( $\mathrm{mL} / \mathrm{min} \mathrm{mg}$ ), $q_{o}$ is the maximum solid phase concentration of solute $(\mathrm{mg} / \mathrm{g}), \theta$ is the effluent flow rate $(\mathrm{L} / \mathrm{min}), m$ is the adsorbent quantity in the column (g), and $V$ is the effluent volume (L). The linear form of Thomas model is given as

$$
\ln \left(\frac{C_{o}}{C_{e}}-1\right)=\frac{K_{T} q_{o} m}{\theta}-\frac{K_{T} C_{o}}{\theta} V .
$$

The kinetic coefficient $K_{T}$ and the adsorption capacity of the column $q_{o}$ can be determined from a plot of $\ln \left(C_{o} / C_{e}-1\right)$ against $t$ at a given flow rate as shown in Figure 11 (shown only for pure titania-coated glass beads column).

The Thomas equation coefficients for As(III) adsorption by all the three types of nanoparticles coated glass beads are given in Table 6.

The values of constants for titania nanoparticles coated glass beads were $K_{T}=0.02 \mathrm{~L} / \mathrm{min} \cdot \mathrm{mg}$ and $q_{o}=0.53 \mathrm{mg} / \mathrm{g}$. The theoretical predictions based on the model parameters are compared in Figure 12 with the observed data (shown only for pure titania-coated glass beads column).

4.8.3. Yoon and Nelson Model. As compared to other models the Yoon and Nelson model, is not only less complicated 
TABLE 7: Yoon-Nelson model parameters for different nanoparticles coated glass beads.

\begin{tabular}{lccc}
\hline Nanoparticles & $k$ & $\tau$ & $q_{o}$ \\
\hline $\mathrm{TiO}_{2}$ & 0.067 & 81.59 & 0.407 \\
$\mathrm{Ag}_{-}-\mathrm{TiO}_{2}$ & 0.058 & 95.48 & 0.477 \\
$\mathrm{Fe}-\mathrm{TiO}_{2}$ & 0.05 & 107.4 & 0.54 \\
\hline
\end{tabular}

TABLE 8: Effect of nanoparticles used on the column breakthrough and exhaustion time.

\begin{tabular}{lcc}
\hline Nanoparticles coated on GB & $\begin{array}{c}\text { Breakthrough } \\
\text { time (hr) }\end{array}$ & $\begin{array}{c}\text { Exhaustion } \\
\text { time (hr) }\end{array}$ \\
\hline $\mathrm{TiO}_{2}$ & 1.67 & 6.67 \\
$\mathrm{Ag}^{-\mathrm{TiO}_{2}}$ & 2.33 & 7.67 \\
$\mathrm{Fe}_{-} \mathrm{TiO}_{2}$ & 3 & 8.33 \\
\hline
\end{tabular}

but also requires no detail related to the characteristics of adsorbate, adsorbent type, and the physical characteristics of the adsorption bed. This model is mainly based on the assumption that for each adsorbate molecule the rate of decrease in the probability of adsorption is proportional to the probability of adsorbate adsorption and the probability of adsorbate breakthrough on the adsorbent [64]. The Yoon and Nelson model equation for a single component system is given as [66]

$$
\frac{C_{e}}{C_{o}}=\frac{1}{1+\exp [k(\tau-t)]} .
$$

The linear form of Yoon and Nelson model is as follows:

$$
t=\tau+\frac{1}{k} \ln \frac{C_{e}}{C_{o}-C_{e}},
$$

where $K$ is the Yoon and Nelson rate constant $(\mathrm{L} / \mathrm{min}), \tau$ is the time required for $50 \%$ adsorbate break through (min), and $t$ is the breakthrough (sampling) time (min). These values can be obtained by plotting $\ln \left[C_{e} /\left(C_{o}-C_{e}\right)\right]$ against $t$ as shown in Figure 13 (shown only for pure titania-coated glass beads column).

The model parameters obtained for the As(III) adsorption on all the three types of titania-based nanoparticles coated glass beads are given in Table 7 .

Alternatively, when $\ln \left[C_{e} /\left(C_{o}-C_{e}\right)\right]$ is zero, $\tau$ can also be obtained from the adsorption time. This is because of the fact that by definition $\tau$ is the adsorption time when $C_{e}$ is one half of $C_{o}$. From these values, the breakthrough curves were calculated. The theoretical curves were then compared with the corresponding experimental data in Figure 14 (both line and dots). Derivation of (28) was based on the definition that at $\tau$, and $50 \%$ breakthrough of the adsorption occurs. Accordingly, at $2 \tau$ the bed should be fully saturated. Because of the symmetrical breakthrough curve, the As(III) adsorbed by titania-coated glass beads is equal to one half of the As(III) entering the column within $2 \tau$ period. This gives rise to the following equation [67]:

$$
q_{o}=\frac{1}{2} C_{o} \theta(2 \tau)=C_{o} \theta \tau
$$

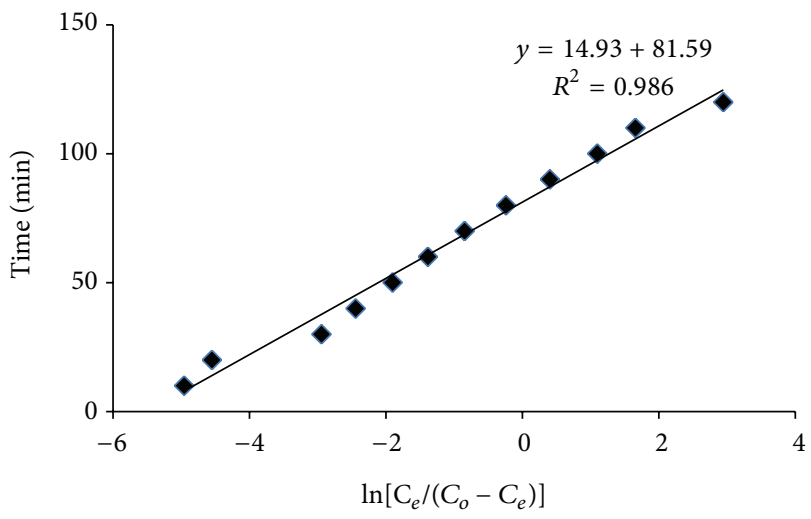

Figure 13: Plot of $\ln \left[C_{e} /\left(C_{o}-C_{e}\right)\right]$ versus time $(t)$.

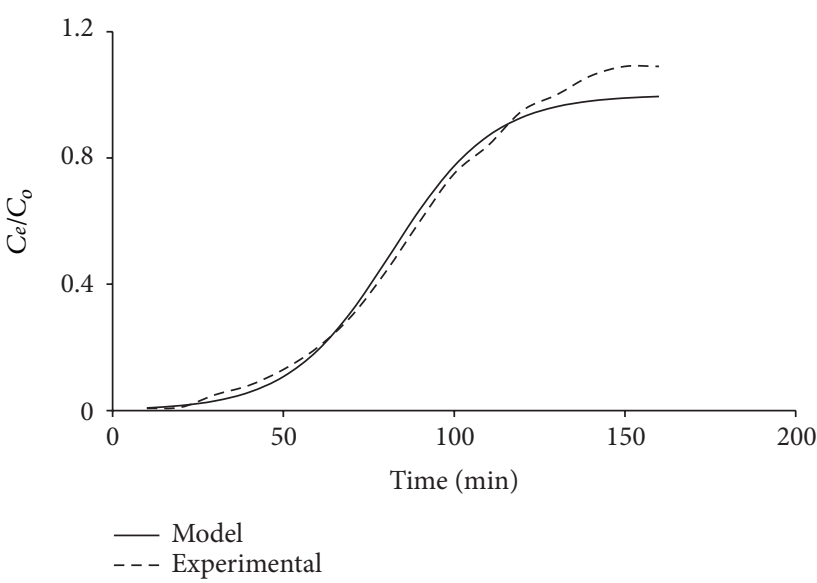

FIgURE 14: Yoon and Nelson model, comparison of predicted and experimental curves.

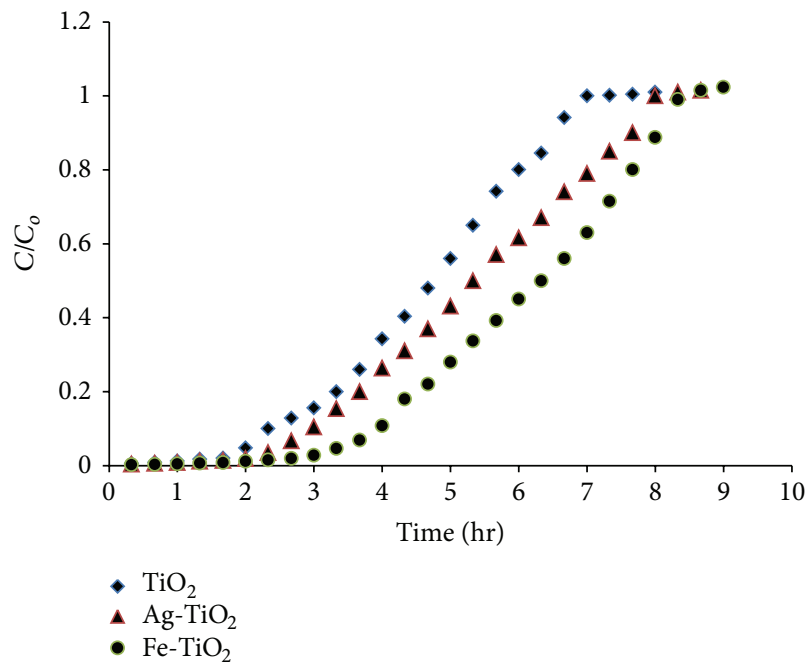

FigURE 15: Effect of nanoparticles used on column parameters. 
This equation develops the relation among the adsorption capacity $\left(q_{o}\right)$ of the column, influent concentration $\left(C_{o}\right)$, flow rate $(\theta)$, and the $50 \%$ breakthrough time $(\tau)$. The value of $q_{o}$ calculated using Yoon and nelson model for all the three types of column is given in Table 7.

4.8.4. Effect of Different Operating Conditions on Column Sorption of As(III). Operational parameters such as flow rate, bed height, arsenic concentration, and variation of nanoparticles are important for column design. The influence of these parameters on the adsorption capacity of nanoparticles was studied for As(III) uptake. The effect of influent $\mathrm{pH}$ on adsorption was not studied here as our previous results revealed that optimum As(III) adsorption on our nanoparticles occurred at $\mathrm{pH} 7$.

(1) Effect of the Nanoparticles Used. In order to know which nanoparticles packed in the column were having the best arsenic removal efficiency, three columns of the same bed depth and diameter $(10 \mathrm{~cm}$ and $1.5 \mathrm{~cm}$, respectively) each packed with the glass beads coated with different nanoparticles were selected. The same arsenic stock solution of $0.5 \mathrm{ppm}$ was used for all of them and the influent flow rate was kept constant at $5 \mathrm{~mL} / \mathrm{min}$ for each. The column breakthrough time and the column exhaustion time for the three different columns, Figure 15 (only plot for pure titania-coated glass beads is shown) are shown in Table 8 .

(2) Effect of Bed Height. To know how much is the effect of bed height on the arsenic removal efficiency, three columns of bed height 10,20 , and $30 \mathrm{~cm}$ of each type of nanoparticles were taken, keeping the influent arsenic concentration at $0.5 \mathrm{ppm}$ and as flow rate at $5 \mathrm{~mL} / \mathrm{min}$, shown in Figure 16 (only plot for pure titania coated glass beads shown). The data obtained is shown in Table 9.

From the data above it is clear that with an increase in bed height the arsenic removal efficiency of column increases, this is because of greater contact time plus more adsorbent for the adsorption of As(III).

(3) Effect of Flow Rate. For this purpose, a column of each nanoparticles (pure, Ag-doped, and Fe-doped titania) was selected. The columns were charged at flow rates of 5 and $10 \mathrm{~mL} / \mathrm{min}$. The influent As(III) concentration was maintained at $0.25 \mathrm{mg} / \mathrm{L}$. The bed depth and column diameters were $10 \mathrm{~cm}$ and $1.5 \mathrm{~cm}$, respectively. The column breakthrough time and the column exhaustion time for the flow rates of 5 and $10 \mathrm{~mL} / \mathrm{min}$ for all the three types of nanoparticles, Figure 17, (only plot for pure titania-coated glass beads shown) are given in Table 10.

It is evident from the results that an increase in flow rate causes a decrease in residence time, which in turn lowers the removal efficiency. With a lower flow rate, the removal efficiency increases due to the increase in residence time.

(4) Effect of Initial Concentration. To determine the effect of influent arsenic concentration on the performance of our columns, three influent arsenic concentrations (i.e., 0.25, 0.5, and $1 \mathrm{ppm}$ ) were selected. Bed depth and column diameter

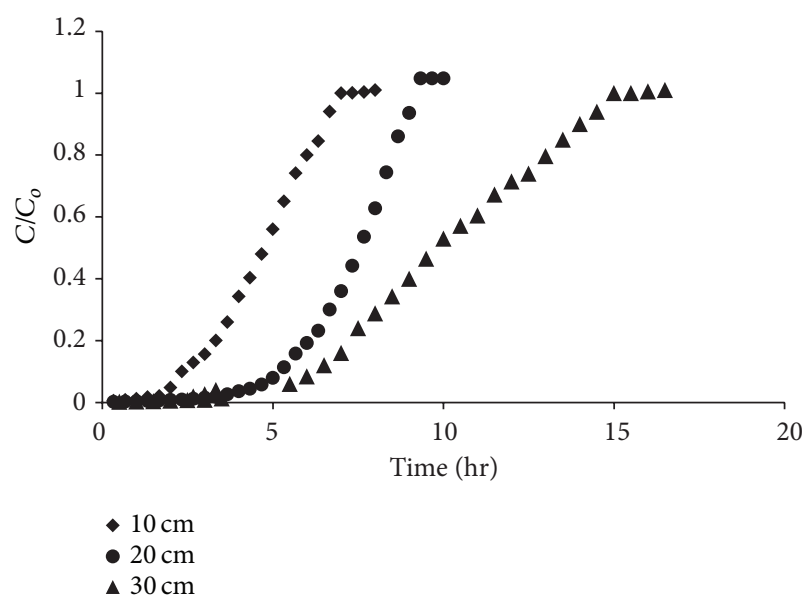

FIGURE 16: Effect of bed height on the column parameters.

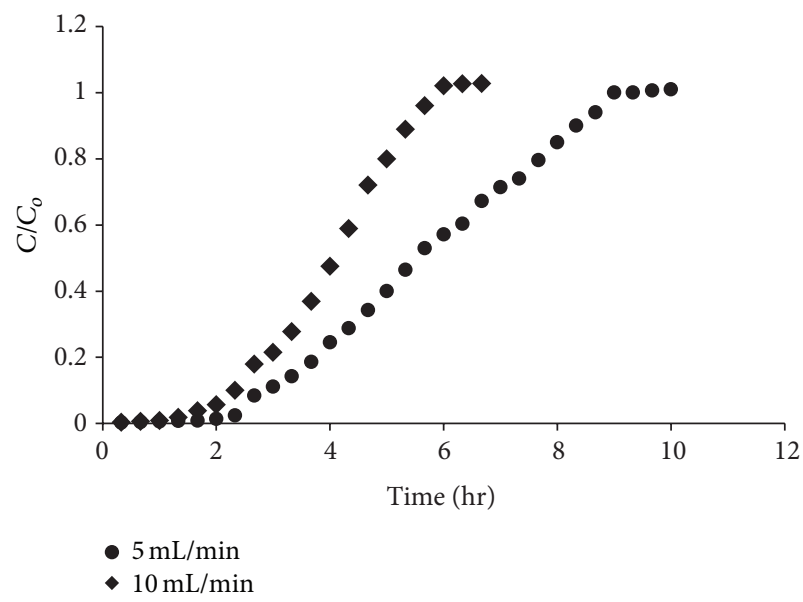

FIGURE 17: Effect of influent flow rate on column parameters.

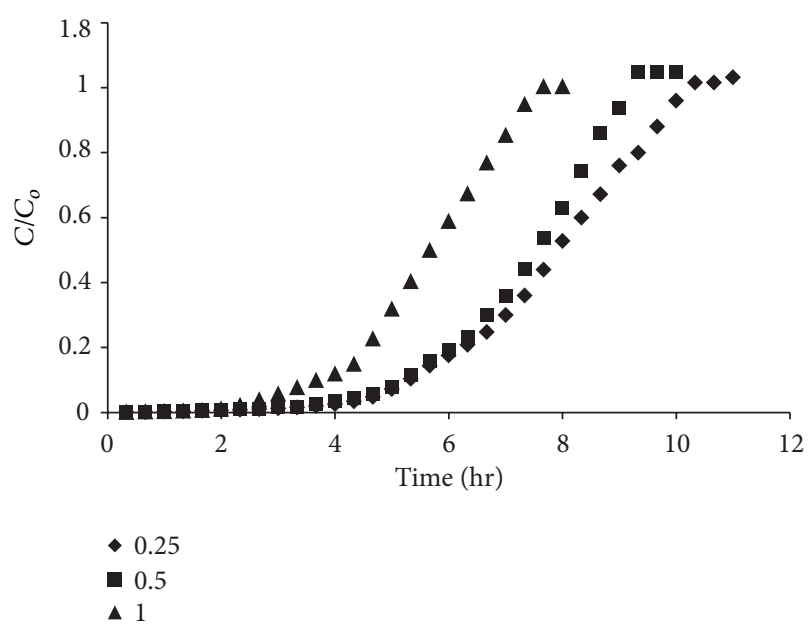

FIGURE 18: Effect of influent concentration on column parameters. 
TABLE 9: Effect of bed height on the column breakthrough and exhaustion time.

\begin{tabular}{lcccccc}
\hline $\begin{array}{l}\text { Nanoparticles } \\
\text { coated on GB }\end{array}$ & $10 \mathrm{~cm}$ & $20 \mathrm{~cm}$ & $30 \mathrm{~cm}$ & $10 \mathrm{~cm}$ & \multicolumn{2}{c}{ Exhaustion time (hr) } \\
\hline $\mathrm{TiO}_{2}$ & 1.67 & 3.67 & 4.5 & 6.67 & $20 \mathrm{~cm}$ & 9 \\
$\mathrm{Ag}-\mathrm{TiO}_{2}$ & 2.33 & 4.33 & 6 & 7.67 & 9.67 & 14 \\
$\mathrm{Fe}_{-}-\mathrm{TiO}_{2}$ & 3 & 5 & 6.5 & 8.33 & 10.67 & 16 \\
\hline
\end{tabular}

TABLE 10: Effect of flow rate on the column breakthrough and exhaustion time.

\begin{tabular}{lcccc}
\hline Nanoparticles coated on glass beads & \multicolumn{2}{c}{ Breakthrough time (hr) } & \multicolumn{2}{c}{ Exhaustion time (hr) } \\
& $5 \mathrm{~mL} / \mathrm{min}$ & $10 \mathrm{~mL} / \mathrm{min}$ & $5 \mathrm{~mL} / \mathrm{min}$ & 7.67 \\
\hline $\mathrm{TiO}_{2}$ & 2.33 & 0.67 & 8.67 & 2.83 \\
$\mathrm{Ag}^{-\mathrm{TiO}_{2}}$ & 3 & 1 & 9 & 3.33 \\
$\mathrm{Fe}-\mathrm{TiO}_{2}$ & 3.67 & 1.33 & 3.67 \\
\hline
\end{tabular}

TABLE 11: Effect of influent concentration on the column breakthrough and exhaustion time.

\begin{tabular}{|c|c|c|c|c|c|c|}
\hline \multirow{2}{*}{ Nanoparticles coated on glass beads } & \multicolumn{3}{|c|}{ Breakthrough time (hr) } & \multicolumn{3}{|c|}{ Exhaustion time (hr) } \\
\hline & $0.25 \mathrm{ppm}$ & $0.5 \mathrm{ppm}$ & $1 \mathrm{ppm}$ & $0.25 \mathrm{ppm}$ & $0.5 \mathrm{ppm}$ & $1 \mathrm{ppm}$ \\
\hline $\mathrm{TiO}_{2}$ & 4.67 & 3.67 & 2 & 10 & 9 & 7.33 \\
\hline $\mathrm{Ag}-\mathrm{TiO}_{2}$ & 5.67 & 4.33 & 2.33 & 11.33 & 9.67 & 8.33 \\
\hline $\mathrm{Fe}-\mathrm{TiO}_{2}$ & 6 & 5 & 2.67 & 11.67 & 10.67 & 8.67 \\
\hline
\end{tabular}

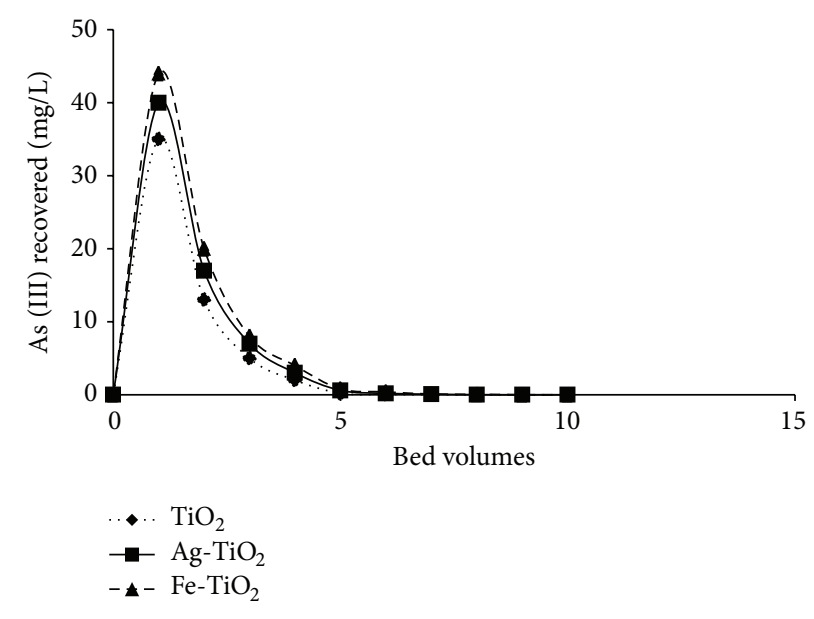

FIGURE 19: As(III) concentration profile during column regeneration.

were maintained at $20 \mathrm{~cm}$ and $1.5 \mathrm{~cm}$, respectively, and flow rate was maintained at $5 \mathrm{~mL} / \mathrm{min}$. All the three types of coated nanoparticles were used, Figure 18 (only plot for pure titaniacoated glass beads is shown). The results found are given in Table 11 .

As expected with increase in influent arsenic concentration, the column breakthrough and column exhaustion times were decreased. This shows that the lower the influent arsenic concentration, the more the efficiency and life of the column.

4.8.5. Column Regeneration and Reuse. For a viable sorption process, easy regeneration and reuse of the column media are necessary. The exhausted $20 \mathrm{~cm}$ bed volume columns (for all the three nanoparticles coated glass beads) after exhaustion were regenerated with $10 \% \mathrm{NaOH}$ solution. During desorption, the arsenic recovery profile is shown in Figure 19. It was found that 10 bed volumes were sufficient for $99 \%$ arsenic recovery from the column. Initially in the first 2-3 bed volumes almost $86 \%$ of the adsorbed arsenic was eluted, and the rest got desorbed in 7 further bed volumes. This clearly shows that the sorption sites of glass beads coated with nanoparticles are easily accessible and also that adsorptiondesorption process is reversible.

After regeneration, the column was rinsed with mild warm deionized water to remove any traces of $\mathrm{NaOH}$ and lower the $\mathrm{pH}$ to normal, as in basic range the adsorption is less efficient. The column was then dried and was subjected 


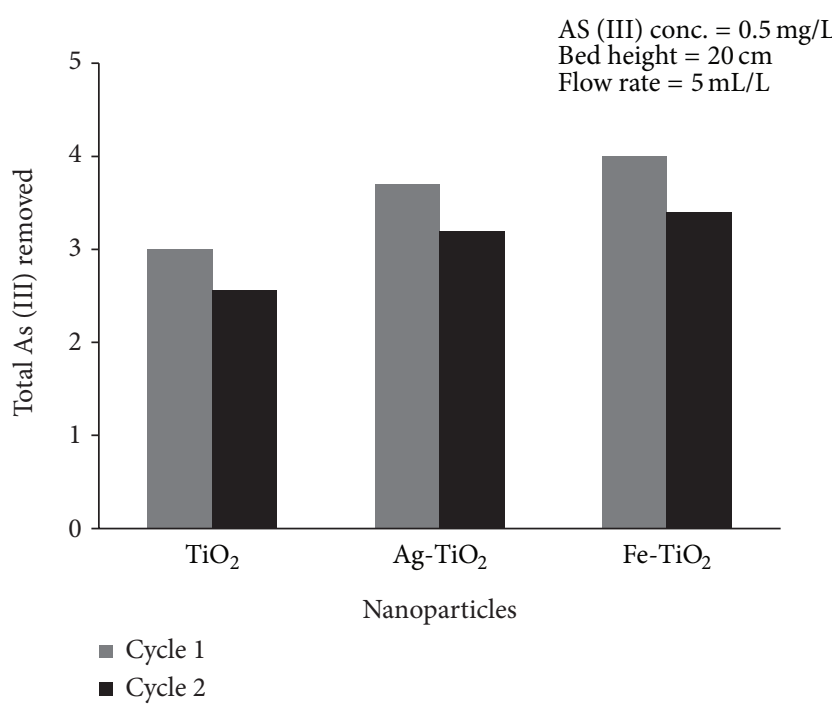

Figure 20: Capacities of different nanoparticles for As(III) removal during two successive cycles.

to the next sorption cycle. Figure 20 shows both the consecutive sorption cycles, from which it is clear that the removal efficiency during the second cycle is decreased by about $10 \%$. Hence, it is clear from Figure 20 that As(III) removal capacities of different nanoparticles coated glass beads during the two consecutive cycles, and the regeneration and reuse of these coated glass beads offers an economical approach for As(III) removal from water.

\section{Conclusions}

This adsorption and column study of titania-based nanoparticles coated on glass beads is carried out to know the fixed bed column performance of these nanoparticles for As(III) removal. These nanoparticles (both in powder and coated form) were found to be efficient in removing As(III) from water at neutral $\mathrm{pH}$ (i.e., $\mathrm{pH}$ 7); any increase or decrease in $\mathrm{pH}$ resulted in a decrease in their efficiency. Metal doping shifted the absorption band of titania from UV into visible region, thus enhancing both its photocatalytic activity and efficiency to adsorb As(III). Among the nanoparticles used, Fe-doped titania gave the best results both in powder and coated form. Thomas and Yoon-Nelson models applied to evaluate column parameters gave results in clear agreement with the practical results. The column once used could be regenerated in a costeffective way using $10 \% \mathrm{NaOH}$ only within 10 bed volumes. Subsequent rinsing of the column with mild warm deionized water for 10-13 bed volumes made the column ready for second sorption cycle. The efficiency of the column was not much affected during the two consecutive cycles.

\section{References}

[1] N. Deedar, A. Irfan, and I. A. Qazi, "Evaluation of the adsorption potential of titanium dioxide nanoparticles for arsenic removal," Journal of Environmental Sciences, vol. 21, no. 3, pp. 402-408, 2009.

[2] E. A. Woolson, Arsenical Pesticides, vol. 7, American Chemical Society, 1975.

[3] B. K. Mandal and K. T. Suzuki, "Arsenic round the world: a review," Talanta, vol. 58, no. 1, pp. 201-235, 2002.

[4] H. Onishi, "Arsenic," in Handbook of Geochemistry, K. H. Wedepohl, Ed., vol. 2, chapter 33, Springer, New York, NY, USA, 1969.

[5] D. Clifford and C. C. Lin, "Ion exchange, activated alumina, and membrane processes for arsenic removal from groundwater," in Proceedings of the 45th Annual Environmental Engineering Conference, University of Kansas, February 1995.

[6] J. C. Ng, J. Wang, and A. Shraim, "A global health problem caused by arsenic from natural sources," Chemosphere, vol. 52, no. 9, pp. 1353-1359, 2003.

[7] C. K. Jain and I. Ali, "Arsenic: occurrence, toxicity and speciation techniques," Water Research, vol. 34, no. 17, pp. 4304-4312, 2000.

[8] C. Abernathy and A. Morgan, "Exposure and health effect," UN Synthesis Report on Arsenic in Drinking Water, World Health Organization, Geneva, Switzerland, 2001, Chapter 3, http://www.who.int/water_sanitation_health/dwq/arsenic3/en/, http://www.who.int/water_sanitation_health/dwq/arsenicun3 .pdf.

[9] National Research Council, Arsenic in Drinking Water, National Academy press, Washington, DC, USA, 2000.

[10] Q. Quamruzzaman, M. Rahman, and K. A. Asad, Effects of Arsenic on Health in Arsenic Contamination, Bangladesh Perspective, ITN-Bangladesh, Dhaka, Bangladesh, 2003.

[11] H. Jézéquel and K. Chu, "Removal of arsenate from aqueous solution by adsorption onto titanium dioxide nanoparticles," Journal of Environmental Science and Health, vol. 41, no. 8, pp. 1519-1528, 2006.

[12] C. K. Jain and I. Ali, "Arsenic: occurrence, toxicity and speciation techniques," Water Research, vol. 34, no. 17, pp. 4304-4312, 2000.

[13] T. Ahmad, M. A. Kahlown, A. Tahir, and H. Rashid, "Arsenic an emerging issue: experiences from Pakistan," in Proceedings of the 30th WEDC International Conference, Vientiane, Laos, 2004.

[14] A. Farooqi, H. Masuda, M. Kusakabe, M. Naseem, and N. Firdous, "Distribution of highly arsenic and fluoride contaminated groundwater from east Punjab, Pakistan, and the controlling role of anthropogenic pollutants in the natural hydrological cycle," Geochemical Journal, vol. 41, no. 4, pp. 213-234, 2007.

[15] WHO, Guidelines for Drinking Water Quality, vol. 1 of Recommendations, World Health Organization, Geneva, Switzerland, 2nd edition, 1993.

[16] WHO, Guidelines for Drinking Water Quality, vol. 1 of Recommendations, World Health Organization, Geneva, Switzerland, 3rd edition, 2004, http://www.who.int/water_sanitation health/dwq/gdwq3rev/en/.

[17] H. Y. Niu, J. M. Wang, Y. L. Shi, Y. Q. Cai, and F. S. Wei, "Adsorption behavior of arsenic onto protonated titanate nanotubes prepared via hydrothermal method," Microporous and Mesoporous Materials, vol. 122, no. 1-3, pp. 28-35, 2009.

[18] J. D. Chwirka, B. M. Thomson, and J. M. Stomp III, "Removing arsenic from groundwater," Journal of American Water Works Association, vol. 92, no. 3, pp. 79-88, 2000.

[19] T.-F. Lin and J.-K. Wu, "Adsorption of arsenite and arsenate within activated alumina grains: equilibrium and kinetics," Water Research, vol. 35, no. 8, pp. 2049-2057, 2001. 
[20] P. Westerhoff, D. Highfield, M. Badruzzaman, and Y. Yoon, "Rapid small-scale column tests for arsenate removal in iron oxide packed bed columns," Journal of Environmental Engineering, vol. 131, no. 2, pp. 262-271, 2005.

[21] Y. Zhang, M. Yang, X.-M. Dou, H. He, and D.-S. Wang, "Arsenate adsorption on an Fe-Ce bimetal oxide adsorbent: role of surface properties," Environmental Science and Technology, vol. 39, no. 18, pp. 7246-7253, 2005.

[22] S. R. Kanel, B. Manning, L. Charlet, and H. Choi, "Removal of arsenic(III) from groundwater by nanoscale zero-valent iron," Environmental Science and Technology, vol. 39, no. 5, pp. 12911298, 2005.

[23] D. Mohan and C. U. Pittman Jr., "Arsenic removal from water/ wastewater using adsorbents: a critical review," Journal of Hazardous Materials, vol. 142, no. 1-2, pp. 1-53, 2007.

[24] M. Borho and P. Wilderer, "Optimized removal of arsenate(III) by adaptation of oxidation and precipitation processes to the filtration step," Water Science and Technology, vol. 34, no. 9, pp. 25-31, 1996.

[25] H. Lee and W. Choi, "Photocatalytic oxidation of arsenite in $\mathrm{TiO}_{2}$ suspension: kinetics and mechanisms," Environmental Science and Technology, vol. 36, no. 17, pp. 3872-3878, 2002.

[26] Y. Kim, C. Kim, I. Choi, S. Rengaraj, and J. Yi, "Arsenic removal using mesoporous alumina prepared via a templating method," Environmental Science and Technology, vol. 38, no. 3, pp. 924931, 2004.

[27] J. G. Hering, P.-Y. Chen, J. A. Wilkie, M. Elimelech, and S. Liang, "Arsenic removal by ferric chloride," Journal of the American Water Works Association, vol. 88, no. 4, pp. 155-167, 1996.

[28] M. C. Dodd, N. D. Vu, A. Ammann et al., "Kinetics and mechanistic aspects of As(III) oxidation by aqueous chlorine, chloramines, and ozone: relevance to drinking water treatment," Environmental Science and Technology, vol. 40, no. 10, pp. 32853292, 2006.

[29] B. D. Kocar and W. P. Inskeep, "Photochemical oxidation of As(III) in ferrioxalate solutions," Environmental Science and Technology, vol. 37, no. 8, pp. 1581-1588, 2003.

[30] M. Pettine, L. Campanella, and F. J. Millero, "Arsenite oxidation by $\mathrm{H}_{2} \mathrm{O}_{2}$ in aqueous solutions," Geochimica et Cosmochimica Acta, vol. 63, no. 18, pp. 2727-2735, 1999.

[31] M. J. Scott and J. J. Morgan, "Reactions at oxide surfaces. 1: oxidation of as(III) by synthetic birnessite," Environmental Science and Technology, vol. 29, no. 8, pp. 1898-1905, 1995.

[32] V. Q. Chiu and J. G. Hering, "Arsenic adsorption and oxidation at manganite surfaces. 1: method for simultaneous of determination of adsorbed and dissolved arsenic species," Environmental Science and Technology, vol. 34, no. 10, pp. 2029-2034, 2000.

[33] M.-J. Kim and J. Nriagu, "Oxidation of arsenite in groundwater using ozone and oxygen," Science of the Total Environment, vol. 247, no. 1, pp. 71-79, 2000.

[34] S. J. Hug and O. Leupin, "Iron-catalyzed oxidation of Arsenic(III) by oxygen and by hydrogen peroxide: $\mathrm{pH}$ dependent formation of oxidants in the Fenton reaction," Environmental Science and Technology, vol. 37, no. 12, pp. 2734-2742, 2003.

[35] H. Yang, W.-Y. Lin, and K. Rajeshwar, "Homogeneous and heterogeneous photocatalytic reactions involving As(III) and $\mathrm{As}(\mathrm{V})$ species in aqueous media," Journal of Photochemistry and Photobiology A, vol. 123, no. 1-3, pp. 137-143, 1999.

[36] M. T. Emett and G. H. Khoe, "Photochemical oxidation of arsenic by oxygen and iron in acidic solutions," Water Research, vol. 35, no. 3, pp. 649-656, 2001.
[37] S. J. Hug, L. Canonica, M. Wegelin, D. Gechter, and U. Von Gunten, "Solar oxidation and removal of arsenic at circumneutral $\mathrm{pH}$ in iron containing waters," Environmental Science and Technology, vol. 35, no. 10, pp. 2114-2121, 2001.

[38] J. Ryu and W. Choi, "Effects of $\mathrm{TiO}_{2}$ surface modifications on photocatalytic oxidation of arsenite: the role of superoxides," Environmental Science and Technology, vol. 38, no. 10, pp. 29282933, 2004.

[39] M. A. Ferguson, M. R. Hoffmann, and J. G. Hering, " $\mathrm{TiO}_{2}$ photocatalyzed As(III) oxidation in aqueous suspensions: reaction kinetics and effects of adsorption," Environmental Science and Technology, vol. 39, no. 6, pp. 1880-1886, 2005.

[40] P. K. Dutta, S. O. Pehkonen, V. K. Sharma, and A. K. Ray, "Photocatalytic oxidation of arsenic (III): evidence of hydroxyl radicals," Environmental Science and Technology, vol. 39, no. 6, pp. 1827-1834, 2005.

[41] T. Nakajima, Y.-H. Xu, Y. Mori et al., "Combined use of photocatalyst and adsorbent for the removal of inorganic arsenic(III) and organoarsenic compounds from aqueous media," Journal of Hazardous Materials, vol. 120, no. 1-3, pp. 75-80, 2005.

[42] S.-H. Yoon and J. H. Lee, "Oxidation mechanism of As(III) in the $\mathrm{UV} / \mathrm{TiO}_{2}$ system: evidence for a direct hole oxidation mechanism," Environmental Science and Technology, vol. 39, no. 24, pp. 9695-9701, 2005.

[43] M. A. Ferguson and J. G. Hering, " $\mathrm{TiO}_{2}$-photocatalyzed As(III) oxidation in a fixed-bed, flow-through reactor," Environmental Science and Technology, vol. 40, no. 13, pp. 4261-4267, 2006.

[44] W.-C. Hung, S.-H. Fu, J.-J. Tseng, H. Chu, and T.-H. Ko, "Study on photocatalytic degradation of gaseous dichloromethane using pure and iron ion-doped $\mathrm{TiO}_{2}$ prepared by the sol-gel method," Chemosphere, vol. 66, no. 11, pp. 2142-2151, 2007.

[45] M. Bissen, M.-M. Vieillard-Baron, A. J. Schindelin, and F. H. Frimmel, " $\mathrm{TiO}_{2}$-catalyzed photooxidation of arsenite to arsenate in aqueous samples," Chemosphere, vol. 44, no. 4, pp. 751-757, 2001.

[46] M. A. Ferguson, M. R. Hoffmann, and J. G. Hering, " $\mathrm{TiO}_{2}$ photocatalyzed As(III) oxidation in aqueous suspensions: reaction kinetics and effects of adsorption," Environmental Science and Technology, vol. 39, no. 6, pp. 1880-1886, 2005.

[47] T. Balaji and H. Matsunaga, "Adsorption characteristics of As(III) and As(V) with titanium dioxide loaded Amberlite XAD-7 resin," Analytical Sciences, vol. 18, no. 12, pp. 1345-1349, 2002.

[48] S. Bang, M. Patel, L. Lippincott, and X. Meng, "Removal of arsenic from groundwater by granular titanium dioxide adsorbent," Chemosphere, vol. 60, no. 3, pp. 389-397, 2005.

[49] P. K. Dutta, A. K. Ray, V. K. Sharma, and F. J. Millero, "Adsorption of arsenate and arsenite on titanium dioxide suspensions," Journal of Colloid and Interface Science, vol. 278, no. 2, pp. 270275, 2004.

[50] M. A. Behnajady, N. Modirshahla, M. Shokri, and B. Rad, "Enhancement of photocatalytic activity of $\mathrm{TiO}_{2}$ nanoparticles by Silver doping: photodeposition versus liquid impregnation methods," Global Nest Journal, vol. 10, no. 1, pp. 1-7, 2008.

[51] C. Sahoo, A. K. Gupta, and A. Pal, "Photocatalytic degradation of Crystal Violet (C.I. Basic Violet 3) on silver ion doped $\mathrm{TiO}_{2}$," Dyes and Pigments, vol. 66, no. 3, pp. 189-196, 2005.

[52] G. L. Liu, D. W. Zhu, S. J. Liao, L. Y. Ren, J. Z. Cui, and W. B. Zhou, "Solid-phase photocatalytic degradation of polyethylenegoethite composite film under UV-light irradiation," Journal of Hazardous Materials, vol. 172, no. 2-3, pp. 1424-1429, 2009. 
[53] U. I. Gaya, "Comparative analysis of ZnO-catalyzed photooxidation of p-chlorophenols," European Journal of Chemistry, vol. 2, no. 2, pp. 163-167, 2011.

[54] S. Valencia, J. M. Marín, and G. Restrepo, "Study of the bandgap of synthesized titanium dioxide nanoparticules using the sol-gel method and a hydrothermal treatment," Open Materials Science Journal, vol. 4, pp. 9-14, 2010.

[55] S. Tandon and J. Gupta, "Measurement of forbidden energy gap of semiconductor by diffuse reflectance technique," Phys Status Solidi B, vol. 38, no. 1, pp. 363-367, 1970.

[56] S. López, S. Castillo, J. Chávez, and K. Díaz, "Síntesis y caracterización óptica, eléctrica y estructural de películas delgadas de $\mathrm{CS}_{2}$ depositadas por el método PECVD," Materia, vol. 8, no. 3, pp. 341-349, 2003.

[57] F. Deniz and S. Karaman, "Removal of an azo-metal complex textile dye from colored aqueous solutions using an agroresidue," Microchemical Journal, vol. 99, no. 2, pp. 296-302, 2011.

[58] M. Islam and R. K. Patel, "Evaluation of removal efficiency of fluoride from aqueous solution using quick lime," Journal of Hazardous Materials, vol. 143, no. 1-2, pp. 303-310, 2007.

[59] S. R. Chowdhury and E. K. Yanful, "Arsenic and chromium removal by mixed magnetite-maghemite nanoparticles and the effect of phosphate on removal," Journal of Environmental Management, vol. 91, no. 11, pp. 2238-2247, 2010.

[60] A. Maiti, S. DasGupta, J. K. Basu, and S. De, "Adsorption of arsenite using natural laterite as adsorbent," Separation and Purification Technology, vol. 55, no. 3, pp. 350-359, 2007.

[61] K. H. Chu, X. Feng, E. Y. Kim, and Y. T. Hung, "Biosorption parameter estimation with genetic algorithm," Water, vol. 3, pp. 175-195, 2011.

[62] Y.S. Ho and G. McKay, "A Comparison of chemisorption kinetic models applied to pollutant removal on various sorbents," Process Safety and Environmental Protection, vol. 76, no. 4, pp. 332-340, 1998.

[63] Y.-S. Ho and A. E. Ofomaja, "Pseudo-second-order model for lead ion sorption from aqueous solutions onto palm kernel fiber," Journal of Hazardous Materials, vol. 129, no. 1-3, pp. 137142, 2006.

[64] N. Öztürk and D. Kavak, "Adsorption of boron from aqueous solutions using fly ash: batch and column studies," Journal of Hazardous Materials, vol. 127, no. 1-3, pp. 81-88, 2005.

[65] H. Zheng, L. Han, H. Ma et al., "Adsorption characteristics of ammonium ion by zeolite 13X," Journal of Hazardous Materials, vol. 158, no. 2-3, pp. 577-584, 2008.

[66] Z. Aksu and F. Gönen, "Biosorption of phenol by immobilized activated sludge in a continuous packed bed: prediction of breakthrough curves," Process Biochemistry, vol. 39, no. 5, pp. 599-613, 2004.

[67] S. H. Lin and C. S. Wang, "Treatment of high-strength phenolic wastewater by a new two-step method," Journal of Hazardous Materials, vol. 90, no. 2, pp. 205-216, 2002. 

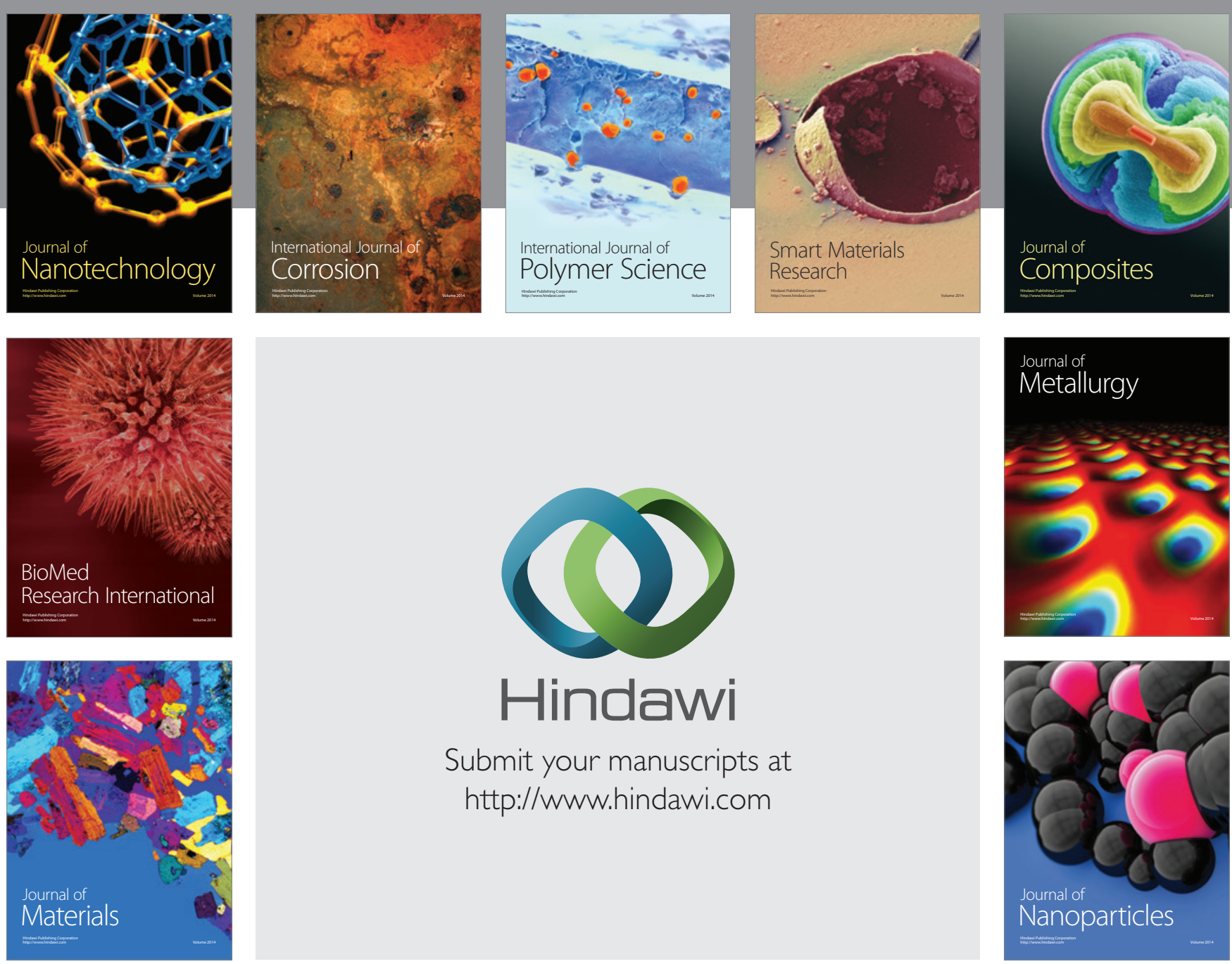

Submit your manuscripts at http://www.hindawi.com
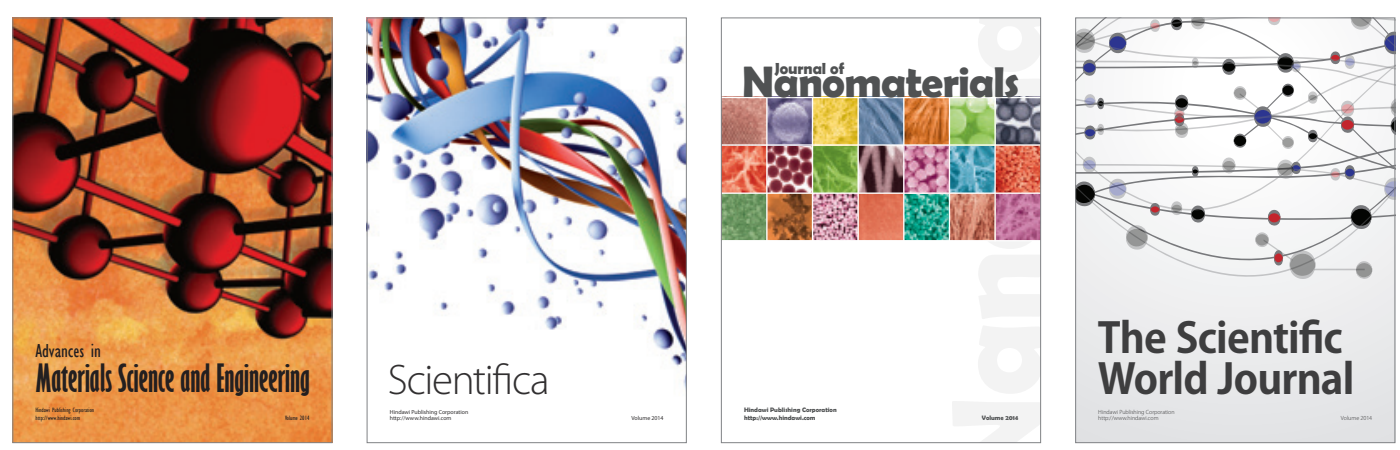

\section{The Scientific World Journal}
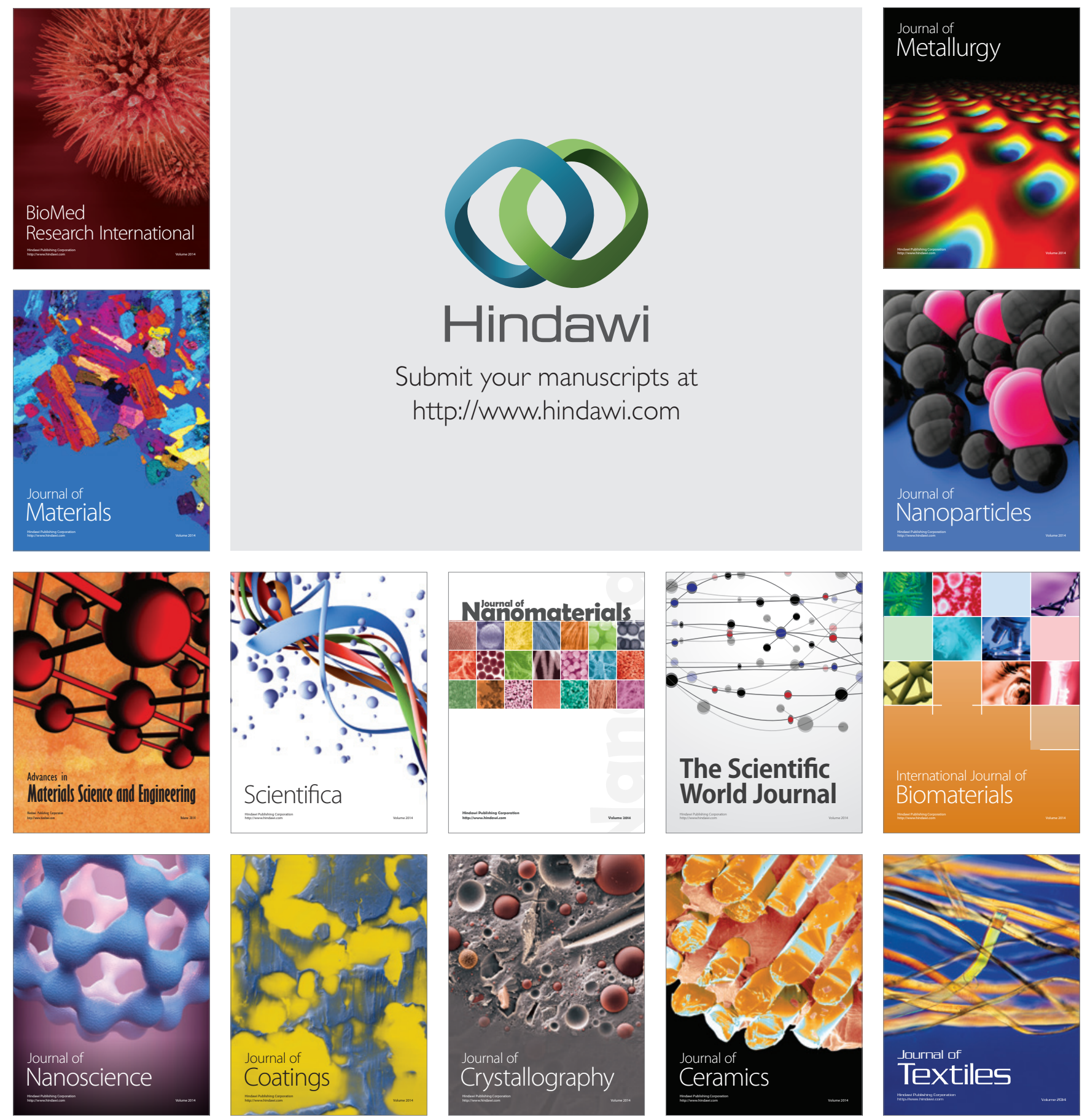